\title{
A comprehensive simulation-based assessment of office building performance adaptability to teleworking scenarios in different Canadian climate zones
}

\author{
Farzam Kharvari $(\bowtie)$, Sara Azimi, William O'Brien \\ Department of Civil and Environmental Engineering, Carleton University, 1125 Colonel by Drive, Ottawa, Ontario, K1S 5B6, Canada
}

\begin{abstract}
Recent studies have shown that office building systems do not adapt well to partial occupancy (e.g., from teleworking) and thus perform suboptimally. As a result, this study aims to assess office building performance adaptability by investigating the impact of four different technologies, including occupancy-based lighting, smart plugs (occupancy-based plug load), demand-controlled ventilation (DCV), occupancy-based thermostat, and their cumulative effect in office buildings in six different Canadian climates. A three-story office building is simulated in EnergyPlus version 9.3.0 under five occupancy scenarios, including 0\% occupancy, 100\% occupancy, 50\% uniformly distributed occupancy across the floor, $50 \%$ consolidated occupancy scenario where occupants work in core zones, and $50 \%$ consolidated occupancy scenario where occupants work in perimeter zones. The results are compared using energy use intensity (EUI), energy use intensity per occupant (EUP), and the corresponding greenhouse gas (GHG) emissions. A total of 180 simulations demonstrate the occupancy-adaptive technologies are generally most beneficial for low occupancy scenarios and milder climates. The results also show the cumulative impact of all these technologies on the potential energy savings is significant in the climates under consideration. Overall, the results show office buildings can improve their performance adaptability during partial occupancy by implementing the studied technologies. Aside from filling in the current knowledge gap in the literature on partial occupancy, the for the first time results of this study systemically demonstrate how each technology performs under different partial occupancy scenarios and how they perform together at each climate.
\end{abstract}

\author{
Keywords \\ partial occupancy; \\ thermostat setpoint; \\ smart plug; \\ demand-controlled ventilation (DCV); \\ lighting
}

\author{
Article History \\ Received: 06 August 2021 \\ Revised: 16 October 2021 \\ Accepted: 04 November 2021 \\ (c) Tsinghua University Press and \\ Springer-Verlag GmbH Germany, \\ part of Springer Nature 2021
}

\section{Introduction}

\subsection{Teleworking and building adaptability}

Lower occupancy is a global phenomenon since some people may work part-time and often offices are keeping some open space for expansion. A major contributor to partial occupancy in offices is the choice of working remotely as a teleworker, a trend that has been accelerated by the COVID-19 pandemic (Schafer 2013; Allen et al. 2015; Elldér 2017; O’Brien and Yazdani Aliabadi 2020). Teleworking can be defined as an umbrella term that includes both working fully or partially outside of a conventional office by using information and communication technology (ICT) in a remote location
(Graizbord 2015). It is recommended as a sustainable solution for reducing the environmental footprint as it reduces the need for transportation and office building space (and corresponding energy consumption) (O'Brien and Yazdani Aliabadi 2020). However, more recent studies on teleworking have shown that the impact of teleworking relies on many different factors such as teleworker behavior (O'Brien and Yazdani Aliabadi 2020), office management and space allocation, number of people and equipment at home, etc. (Nakanishi 2015). Among all these factors, building performance adaptability plays a key role in determining the impact of teleworking on reducing environmental footprint. In this study, building adaptability is defined as the ability of buildings to adapt to partial

E-mail: farzamkharvari@cmail.carleton.ca 
occupancy through energy-saving technologies.

On the other hand, buildings are typically designed for worst-case scenarios (e.g., ventilation and cooling are designed for full capacity) and this is a formidable hurdle for building adaptability. For instance, Yang and Becerik-Gerber's (2014a, b) study on occupancy data of buildings has shown that actual occupancy in office buildings falls between $50 \%$ and $70 \%$ on weekdays while the assumption in the building industry is that buildings operate under full occupancy scenario. Moreover, the occupancy profiles for the full occupancy scenario were developed during the 1980s when teleworking was in its infancy due to technological limitations (Abushakra et al. 2004). Furthermore, studies have found that many office building systems, such as lighting or heating, ventilation, and air conditioning (HVAC) equipment, are operating at full capacity, regardless of occupancy, therefore wasting energy (O’Brien and Gunay 2019; Afroz et al. 2020). This is evidenced by the fact that energy consumption of buildings during the COVID-19 pandemic has not dropped significantly despite the fact that people were working from home (John 2020; Katz 2020; Meier 2020). For instance, the electricity use in the Empire State building only dropped by $28 \%$ although it was mainly unoccupied during the pandemic (Meier 2020). Therefore, building adaptability becomes an important issue when it comes to teleworking since offices are likely to have significantly lower occupancy than design conditions in the near to medium term (Ouf et al. 2019). As a result, it is important to assess the energy use of office buildings under various occupancy scenarios since they will be partially occupied or unoccupied during teleworking.

\subsection{How far have we come?}

Although studies on building adaptability to occupants' presence are relatively new and emerging, the previous efforts in overcoming the building adaptability issues are reviewed in this part of the study. Accordingly, Jemaa et al.'s (2018) study on demand-controlled ventilation (DCV) showed potential savings between $8 \%$ and $16 \%$ are possible based on the number of occupants in buildings although these numbers decrease when the minimum ventilation rate is higher. Peng et al.'s (2017) study on DCV in a cooling system demonstrated $20.3 \%$ savings by implementing DCV and modifying the thermostat based on occupant presence. Abuimara et al.'s (2019) study on DCV illustrated that greater savings is achievable under realistic occupancy scenarios compared to standard occupancy schedules. O’Brien and Gunay's (2019) study showed that the optimal lighting control zone size is smaller for lower occupancy levels than standards. Besides, many of these technologies work based on occupancy sensors which are gaining importance since they control building systems and reduce waste based on the measured presence of occupants (O'Brien et al. 2017). While most of these studies have focused on HVAC systems and lighting, other areas such as the impact of thermostat-related strategies or plug loads have not been investigated systematically based on occupancy. More importantly, a comprehensive study on the presence of occupants and their distribution has not been conducted to date. While the literature shows that teleworking has not been historically widespread (e.g., one day per week), COVID is expected to completely change the way we work in the future since some employees now prefer teleworking over traditional working arrangements (BBC 2020; Wardell and Gittens 2020).

\subsection{Aim and research questions}

To address the aforementioned shortcomings in the literature, this study aims to assess office building performance adaptability under five different occupancy scenarios by investigating the impact of four different technologies, including occupancy-based lighting, smart plugs (occupancybased receptacles), demand-controlled ventilation (DCV), occupancy-based thermostat, and their cumulative effect in office buildings. To achieve this aim, the energy use intensity (EUI), energy use intensity per occupant (EUP), and associated GHG emissions are investigated in a medium Canada's National Energy Code for Buildings (NECB)-compliant office building under five different teleworking scenarios in six Canadian climates. Each story of the building has four perimeter zones and a core zone but the total area of perimeter zones is equivalent to the area of the core zone. We studied the performance of four occupant-adaptive technologies using five different occupancy scenarios and six climates.

Each technology along with a case that includes all technologies (compound effect) is investigated for each occupancy scenario under six different Canadian climates. Accordingly, this study attempts to answer the following research questions (RQ):

- RQ1. What is the energy impact of teleworking on office buildings when 0\%,50\%, and 100\% occupancy? (Occupancy Impact)

- RQ2. How do the energy use intensity (EUI) and energy use intensity per person (EUP) of offices change based on occupant distribution within the building? (Distribution Impact)

- RQ3. What is the energy impact of occupancy-based controls and technologies? (Distribution Impact/Technology Impact)

- RQ4. How well can office buildings adapt to partial occupancy in different office arrangements (i.e., when occupants work in perimeter zones or core zones)? (Adaptability)

To answer the RQs, this study first describes the simulation 
model (Section 2.1) and scenarios in detail (Section 2.2). Then, technologies as well as the way they are modeled in the simulation are described in Section 2.3. Metrics for energy comparison are also explained in Section 2.4. After that, the results for 180 simulations are presented based on the technologies that were implemented in the simulations (Sections 3.2 to 3.6). Important findings of this study are discussed in Section 4.

Since the current literature on partial occupancy is scarce, the present study systematically develops a framework for future use of the aforementioned technologies in different occupancy scenarios to address the current gaps in the literature. Furthermore, this study creates a ranking system for each technology under various occupancy scenarios in different climates (Section 4.4). The developed framework and results are critical for informing the design and operation of office buildings - particularly in the realm of increased levels of telework.

\section{Research methodology}

Figure 1 shows the overall research method of this paper. First, a reference base case model for offices that is widely used for code and policy development was acquired. Then, four technologies including demand-controlled ventilation (DCV), occupancy-based lighting, smart plugs, and thermostat setpoints are investigated and compared to the base case. In the end, the compound effect of all controls is investigated as well. This section of the article presents the building model (Section 2.1), scenarios analysis: scenarios (Section 2.2), technologies for scenarios (Section 2.3), and energy comparison metrics (Section 2.4).

\subsection{Building model}

In this study, the primary model was a three-story office building with five thermal zones, including east, west, south, and north zones plus a core zone which was modeled based on the National Energy Code of Canada for Buildings (NECB) using EnergyPlus version 9.3.0 (DOE 2020). The total floor area of perimeter zones is equivalent to the floor area of the core zone since part of the present study aims at investigating the effect of occupancy profiles on the energy use when $50 \%$ of occupants are working in the core zone (Scenario 3-A, defined in Section 2.2) and when they work in the perimeter zones (Scenario 3-B, defined in Section 2.2) (Figure 2).

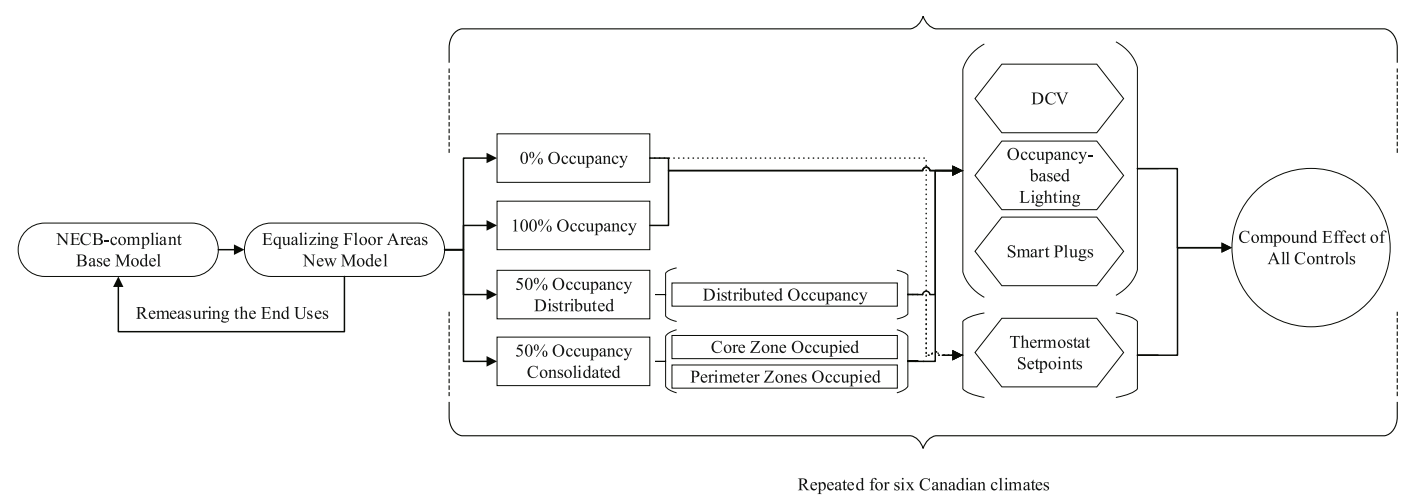

Fig. 1 An overview of the research method; an NECB-compliant base model was acquired and then the floor area of its perimeter zones and core zone were equalized so that we can assess the impact of $50 \%$ consolidated occupancy. Then, five scenarios were investigated using the four technologies and a final strategy in which the compound effect of all controls/technologies are investigated. The entire process is repeated for six Canadian climate zones

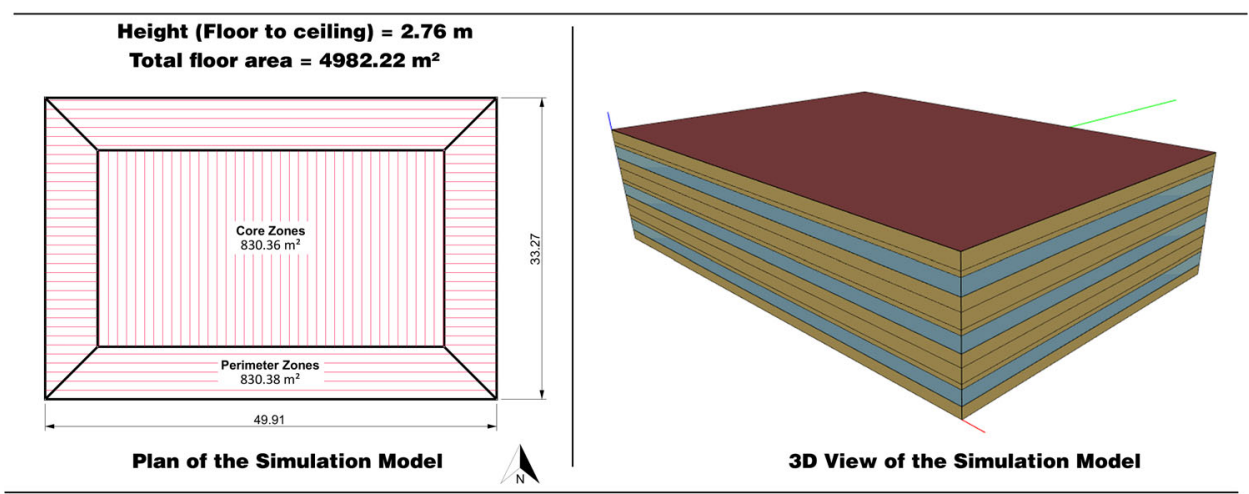

Fig. 2 The simulation model in EnergyPlus; the model is the reference building model for medium office buildings 
Table 1 shows the most important simulation parameters in this study. It should be noted that this reference building was selected for the assessment of technologies in typical office spaces while other factors such as building orientation, façade design, window-to-wall ratio, etc. contribute to the energy use of buildings.
Table 2 shows the $R$-values and $U$-values for walls, foundation, and roof of the model that were extracted from the National Energy Code of Canada (NECB) for buildings in six Canadian climates based on their heating degree days (HDD), with $18^{\circ} \mathrm{C}$ being the base temperature, and KöppenGeiger classification (Chen and Chen 2013; Mazzeo et al.

Table 1 Simulation parameters

\begin{tabular}{|c|c|}
\hline Parameter & Value \\
\hline Maximum number of occupants & 250 people \\
\hline Window-to-wall ratio & $47.68 \%$ \\
\hline Zone net floor area per person & $19.92 \mathrm{~m}^{2} /$ person \\
\hline Occupant heating gain & $130 \mathrm{~W} /$ person \\
\hline Lighting |lighting power density (LPD) & $175.37 \mathrm{~W} /$ person $\mid 8.79 \mathrm{~W} / \mathrm{m}^{2}$ \\
\hline Plug load & $10.27 \mathrm{~W} / \mathrm{m}^{2}$ \\
\hline Infiltration rate & $0.00025 \mathrm{~m}^{3} /\left(\mathrm{s} \cdot \mathrm{m}^{2}\right)$ \\
\hline Outdoor airflow per person & $0.00863 \mathrm{~m}^{3} /(\mathrm{s} \cdot$ person $)$ \\
\hline Economizer control type & Fixed dry bulb \\
\hline Economizer maximum limit dry bulb temperature & $18^{\circ} \mathrm{C}$ \\
\hline Economizer minimum limit dry bulb temperature & $5^{\circ} \mathrm{C}$ \\
\hline Economizer lockout type & Lockout with compressor \\
\hline HVAC type & Baseboards connective water heaters and VAV with Reheat \\
\hline Heating coil fuel type & Natural gas \\
\hline Boiler efficiency & 0.95 \\
\hline Chiller type & Scroll-electric \\
\hline Chiller reference COP & 4.5 \\
\hline Supply air temperature setpoint & $13^{\circ} \mathrm{C}$ \\
\hline Supply air temperature setpoint (thermostat) & Varies \\
\hline
\end{tabular}

Table $2 R$-values and $U$-values for different surfaces in six different climates of Canada

\begin{tabular}{|c|c|c|c|c|c|c|c|c|c|c|c|c|}
\hline \multirow[b]{2}{*}{ Location } & \multicolumn{3}{|c|}{ Climate } & \multirow{2}{*}{$\begin{array}{c}\text { HDD of } \\
\text { the city } \\
\left({ }^{\circ} \mathrm{C} \cdot \text { day }\right)\end{array}$} & \multicolumn{2}{|c|}{ Walls } & \multicolumn{2}{|c|}{ Foundation } & \multicolumn{2}{|c|}{ Roof } & \multicolumn{2}{|c|}{ Windows } \\
\hline & $\begin{array}{l}\text { HDD } \\
\left({ }^{\circ} \mathrm{C} \cdot \text { day }\right)\end{array}$ & Zone & $\begin{array}{l}\text { Köppen-Geiger } \\
\text { classification }\end{array}$ & & $\begin{array}{c}U \text {-value } \\
\left(\mathrm{W} /\left(\mathrm{m}^{2} \cdot \mathrm{K}\right)\right)\end{array}$ & $\begin{array}{c}R \text {-value } \\
\left(\mathrm{m}^{2} \cdot \mathrm{K} / \mathrm{W}\right)\end{array}$ & $\begin{array}{c}U \text {-value } \\
\left(\mathrm{W} /\left(\mathrm{m}^{2} \cdot \mathrm{K}\right)\right)\end{array}$ & $\begin{array}{c}R \text {-value } \\
\left(\mathrm{m}^{2} \cdot \mathrm{K} / \mathrm{W}\right)\end{array}$ & $\begin{array}{c}U \text {-value } \\
\left(\mathrm{W} /\left(\mathrm{m}^{2} \cdot \mathrm{K}\right)\right)\end{array}$ & $\begin{array}{c}R \text {-value } \\
\left(\mathrm{m}^{2} \cdot \mathrm{K} / \mathrm{W}\right)\end{array}$ & $\begin{array}{c}U \text {-value } \\
\left(\mathrm{W} /\left(\mathrm{m}^{2} \cdot \mathrm{K}\right)\right)\end{array}$ & SHGC \\
\hline $\begin{array}{l}\text { Vancouver, } \\
\text { BC }\end{array}$ & $<3000$ & 4 & $\begin{array}{c}\mathrm{Cfb} \\
\text { (oceanic climate) }\end{array}$ & 2903 & 0.315 & 3.175 & 0.757 & 1.321 & 0.193 & 5.181 & 2.1 & 0.31 \\
\hline $\begin{array}{l}\text { Toronto, } \\
\text { ON }\end{array}$ & $\begin{array}{c}3000- \\
3999\end{array}$ & 5 & $\begin{array}{c}\text { Dfa } \\
\text { (hot-summer } \\
\text { humid continental } \\
\text { climate) }\end{array}$ & 3721 & 0.278 & 3.597 & 0.757 & 1.321 & 0.156 & 6.410 & 1.9 & 0.31 \\
\hline $\begin{array}{l}\text { Ottawa, } \\
\text { ON }\end{array}$ & $\begin{array}{c}4000- \\
4999\end{array}$ & 6 & $\begin{array}{c}\text { Dfb } \\
\text { (warm-summer } \\
\text { humid continental } \\
\text { climate) }\end{array}$ & 4523 & 0.247 & 4.049 & 0.757 & 1.321 & 0.156 & 6.410 & 1.9 & 0.31 \\
\hline $\begin{array}{l}\text { Edmonton, } \\
\mathrm{AB}\end{array}$ & $\begin{array}{c}5000- \\
5999\end{array}$ & $7 \mathrm{~A}$ & $\begin{array}{c}\text { Dfb } \\
\text { (warm-summer } \\
\text { humid continental } \\
\text { climate) }\end{array}$ & 5198 & 0.210 & 4.762 & 0.757 & 1.321 & 0.138 & 7.246 & 1.9 & 0.31 \\
\hline $\begin{array}{l}\text { Whitehorse, } \\
\text { YK }\end{array}$ & $\begin{array}{c}6000- \\
6999\end{array}$ & $7 \mathrm{~B}$ & $\begin{array}{c}\text { Dsc } \\
\text { (subarctic climate) }\end{array}$ & 6753 & 0.210 & 4.762 & 0.757 & 1.321 & 0.138 & 7.246 & 1.9 & 0.31 \\
\hline $\begin{array}{l}\text { Resolute, } \\
\text { NU }\end{array}$ & $>7000$ & 8 & $\begin{array}{c}\mathrm{ET} \\
\text { (tundra climate) }\end{array}$ & 11874 & 0.183 & 5.464 & 0.379 & 2.638 & 0.121 & 8.264 & 1.4 & 0.31 \\
\hline
\end{tabular}


2020). Similarly, the overall transmittance, as well as solar heat gain coefficient (SHGC), were based on the NECB standard (NRCan 2017). Prior to running the simulations for the study, the base case model results were compared to ASHRAE's international benchmark (ASHRAE 2014). The results were similar and the models were deemed functioning as expected. Then, the scenario analysis is repeated for six Canadian climates, which are presented in Table 2, resulting in a total of 180 simulation runs. Each climate is represented by a city in that specific climate, and cities are selected based on the criteria of having an average HDD in their specific climate or being a major city in that climate.

\subsection{Scenarios analysis: scenarios}

Five main scenarios are included in this study that all rely on the occupancy levels, including $0 \%, 50 \%$ (consolidated in the core zone, consolidated in perimeter zones, and distributed), and $100 \%$ of the standard occupancy schedule. For Scenario 3, simulations are carried out twice; in the first run, core zones are simulated as occupied, and in the second run, the perimeter zones are simulated as occupied. The hypothesis is that end-use energy consumption is reduced in this scenario since half of the building can work with reduced lighting and plug loads, and relaxed temperature setpoints. The $0 \%$ occupancy scenario (Scenario 1) indicates the building's ability to adapt to $0 \%$ occupancy when all employees are teleworking. In brief, the five investigated scenarios include:

1. $0 \%$ occupancy where no one is present in the building (Scenario 1)

2. 50\% distributed occupancy where $50 \%$ of the total number of occupants are distributed evenly in the building (in the core zone and perimeter zones) (Scenario 2 - distributed)

3. 50\% consolidated occupancy with occupied core zones where $50 \%$ of the total number of occupants are working in the core zone (Scenario 3 - consolidated in core)

4. 50\% consolidated occupancy with occupied perimeter zones where $50 \%$ of the total number of occupants are working in the perimeter zones (Scenario 3 - consolidated in perimeter)

5. 100\% occupancy (full occupancy) where the building follows the full occupancy schedule based on the NECB occupancy schedule which is similar to ASHRAE 90.1 (NRCan 2017; ASHRAE 2019a) (Scenario 4). (All occupancy scenarios are shown in Figure 5 in Section 2.3.2). It should be noted that buildings almost never reach full occupancy (Ouf et al. 2019). Most likely this would occur if there is hoteling (i.e., scheduled workstation-sharing), whereby the actual number of building users may greatly exceed the number of desks (e.g., $50 \%$ or more).

The HVAC equipment was sized with using the base case occupancy scenario for the base model and then this sizing was used for all other occupancy scenarios to make sure that the sizing does not change based on occupancy. It should be noted that in this study, the sizing was enough to meet the required demand in all climates. However, in terms of the adaptability of buildings, HVAC sizing plays an important role in the total energy use of buildings as a small HVAC size can result in the constant operation of the system. On the other hand, large HVAC sizes can result in short-cycling in which the systems turn on and off frequently causing problems such as hot and cold spots or humidity. The simulation scenarios are summarized in Table 3 and then explained in detail.

\subsection{Technologies for scenarios}

\subsubsection{Plug loads based on plug load equation and modeling smart plugs in EnergyPlus}

Plug loads in the base model follow the typical schedule and watts per floor area. In this study, we model plug loads as a function of the number of occupants present. In this regard, a recent paper on plug load calculations developed an equation that provides plug loads based on occupancy $\left(\mathrm{W} / \mathrm{m}^{2}\right)$ (Gunay et al. 2016). Accordingly, this study uses Eq. (1) to simulate the occupancy-based plug loads. This equation is valid for all hours of occupancy and vacancy.

$y=\frac{x-d}{c}$

where $c$ and $d$ are constants $(c=0.00703, d=-0.0222)$ and $x$, which is the instantaneous occupant density, is 0.05 (person $/ \mathrm{m}^{2}$ ). As a result, the total plug load $(y)$ is $10.27 \mathrm{~W} / \mathrm{m}^{2}$ when the entire building is occupied by 250 people. The equation above was incorporated in EnergyPlus via a schedule for simulating the occupancy-based plug loads. The minimum plug load is $3.16 \mathrm{~W} / \mathrm{m}^{2}$ when the building is completely empty and it is $9.56 \mathrm{~W} / \mathrm{m}^{2}$ when it is completely occupied in the occupancy daily profile due to the 0.9 fraction in occupancy schedule (Figure 5). This method allows an exact assessment of the impact of smart plugs on plug loads since it is occupant-based and determines the plug loads based on the presence of occupants.

Although there is no built-in feature for including smart plugs in EnergyPlus, this study measures the effect of smart plugs on the electricity load of buildings based on available data. A comprehensive literature review was carried out to investigate the effect of smart plugs on electricity use. Out of 26 related research papers, five illustrated the potential savings that ranged from $9 \%$ of monthly savings per workstation to $60 \%$ for switching equipment off for nonworking hours 
Table 3 A summary of investigated scenarios

\begin{tabular}{l}
\hline \\
\cline { 5 - 6 }
\end{tabular}

(Ghosh et al. 2013; Vuppala and Kiran Kumar 2013; Hafer et al. 2017; Doherty and Trenbath 2019; Jenkins et al. 2019). However, the majority of findings suggested that electricity use savings from smart plugs is approximately $25 \%$. Evidence from large datasets also suggests that the average saving potential of smart plugs is approximately 25\% when they are used in buildings (Mercier and Moorefield 2011; Metzger et al. 2012). In the simulations, the effect of smart plugs is simulated by applying this $25 \%$ saving to the total electricity load of the building through schedules in EnergyPlus. This is the assumed average effective value when a schedule timer, load-sensing, or both features are available in smart plugs used (Metzger et al. 2012). The 25\% is directly applied to the electricity use of plug loads for $100 \%$ occupancy and $50 \%$ distributed scenarios. For the 50\% consolidated scenario, the $25 \%$ saving is only applied to the occupied zones (meaning the impact is reduced to $12.5 \%$ ). The saving potential is not applied to $0 \%$ scenario or permanently unoccupied zones since such data was not available. Figure 3 shows the relationship between plug loads and occupant counts and how savings were applied to the base case plug loads. Figure 4 shows a typical week based on the described approach.

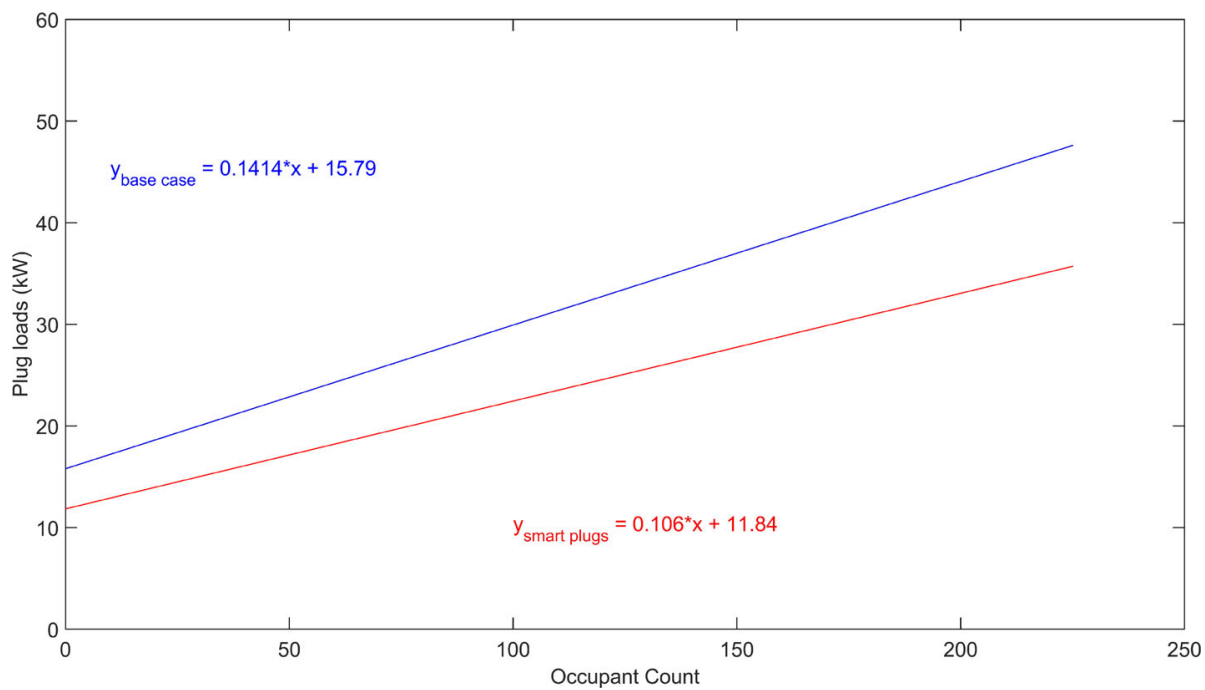

Fig. 3 Relationship between plug loads and occupant count; note that occupant count never reaches 250 due to the maximum fraction of 0.9 in occupancy schedules. The figure shows using smart plugs reduces the $y$-intercept and slope of the line by $25 \%$. $y$-intercept never reaches zero in this case because of the reserved plug loads for occupancy-independent activities within the buildings 


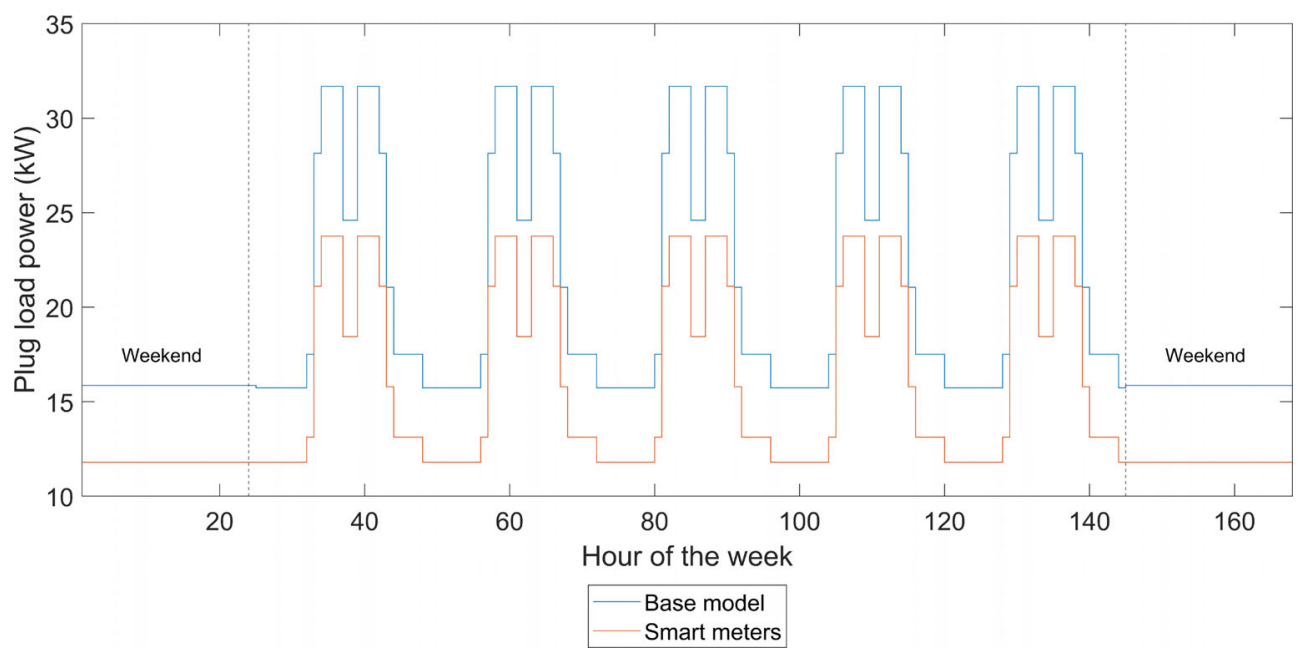

Fig. 4 A typical week for building-level plug loads comparing smart plugs and the base model during the full occupancy scenario

\subsubsection{Occupancy-based lighting}

It is assumed that the lighting is carefully controlled to be on in the building area (workspace) that is associated with the occupant. Plus, another $5 \%$ is on for security and safety purposes. For occupancy-based lighting, the lighting power per floor area was normalized $\left(\mathrm{W} / \mathrm{m}^{2}\right)$ to occupancy. Accordingly, the normalized lighting power is $175.4 \mathrm{~W} /$ person (base case) which is used in EnergyPlus. This is equivalent to assuming that only the lights at the occupants' workspace are on when they are present. To model the occupancy-based lighting controls, a schedule was created for lights that follow the occupancy schedules. $5 \%$ of the total lighting power is constantly on in the schedules accounting for security, hallways, etc. Accordingly, the occupancy-based lighting follow the occupancy schedules plus $5 \%$ of the total lighting power in the schedules (Figure 5).

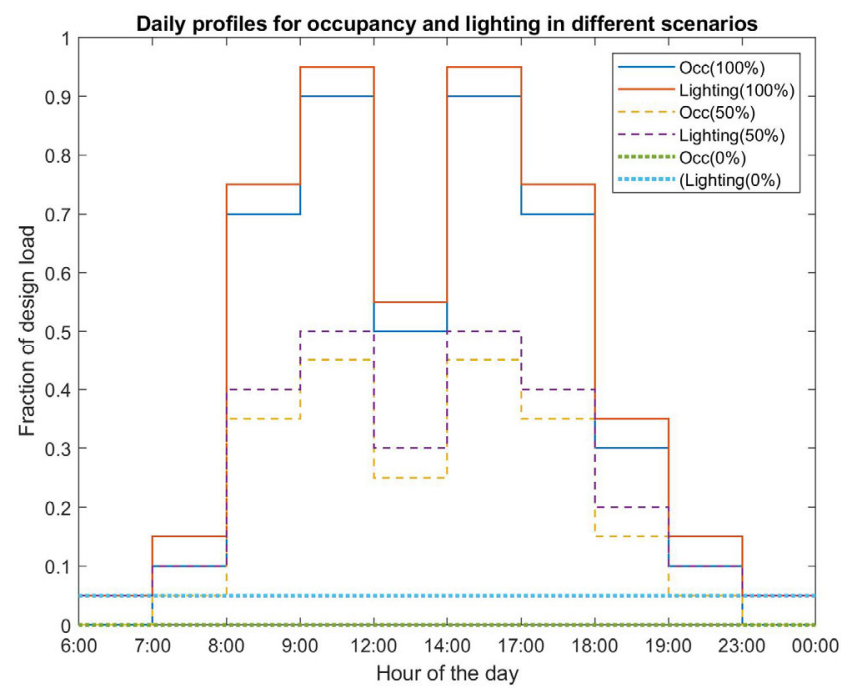

Fig. 5 Occupancy and lighting profiles for occupancy-based lighting. Weekends follow the schedule for unoccupied hours (23:00 to 7:00)
For instance, the fraction of the occupancy schedule in the full occupancy scenario is 0.9 , which is equivalent to 225 people in the building, from 14:00 to 17:00 (Figure 5). The lighting power for 225 people is $39,458.9 \mathrm{~W}$ which is $4,384 \mathrm{~W}$ less than the total lighting power (equals $250 \times 175.4 \mathrm{~W} /$ person). $5 \%$ of the total lighting power is $2,192.2 \mathrm{~W}$. Figure 6 shows a typical week with the base model and occupancy-based lighting based on our approach.

\subsubsection{Occupancy-based thermostat setpoints}

To model the occupancy-based thermostat, all occupied spaces follow the standard schedules of NECB. In zones that are permanently empty (i.e., $0 \%$ case or the empty zones of the consolidated cases), thermostat setpoints for heating are reduced from the schedule (including $18{ }^{\circ} \mathrm{C}, 20^{\circ} \mathrm{C}$, and $22{ }^{\circ} \mathrm{C}$ ) to $17^{\circ} \mathrm{C}$ (Figure 7). It should be noted that cooling setpoints were not manipulated since the air system is turned off at night. In contrast, the heating setpoint is setback from the day because a hydronic system is used to maintain it even when the air handling units are shut off.

\subsubsection{Demand-controlled ventilation (DCV)}

The DCV was not activated in the base model and the NECB does not require it for office buildings. In this study, the "proportional control based on design occupancy" method in EnergyPlus was used for modeling the demand-controlled ventilation (DCV). This method determines the minimum outside airflow rate to be provided by the mixed air box of the AHU. The flow rate is based on the design occupancy (occupancy schedules multiplied by occupant density) and the minimum outdoor flow rate per person of $0.00863 \mathrm{~m}^{3} /$ (s.person). Table 4 summarizes the technology upgrades to the base model and method for implementation in EnergyPlus. Figure 8 illustrates a typical week of how DCV was implemented using this approach. This method is chosen 


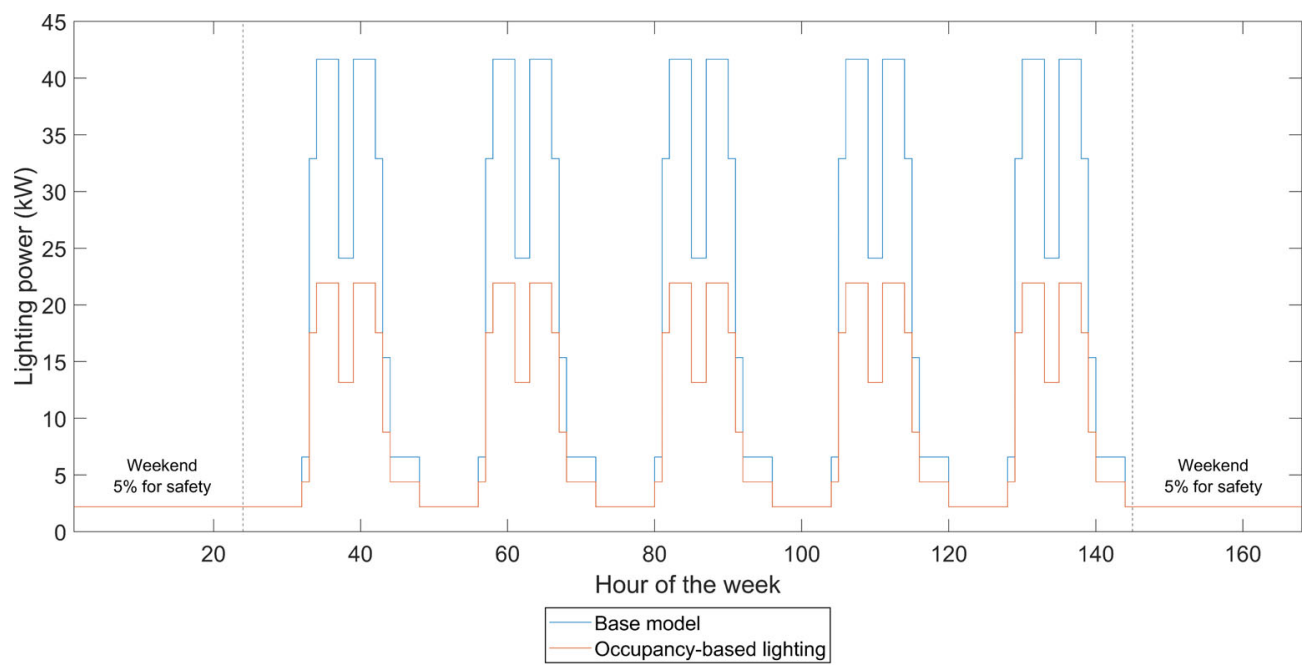

Fig. 6 A typical week for occupancy-based lighting

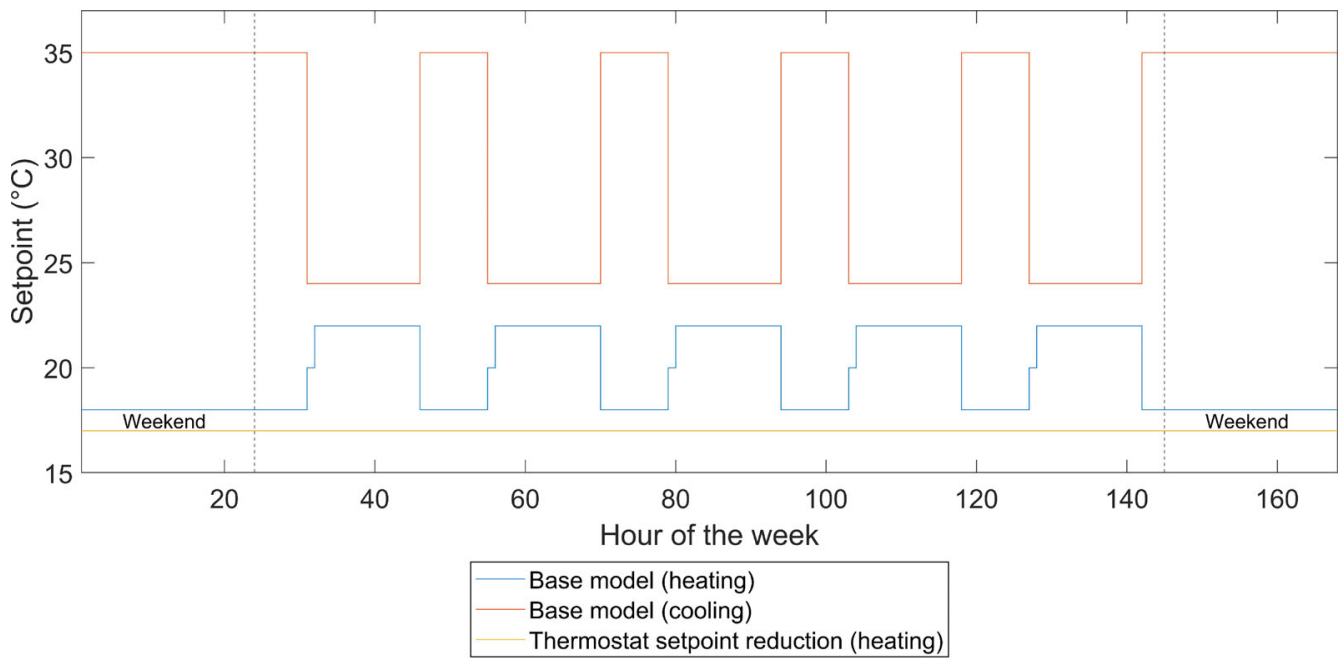

Fig. 7 Thermostat setpoints in the base model and thermostat setpoint strategy

Table 4 Summary of technology upgrades and method for implementation in EnergyPlus

\begin{tabular}{lll}
\hline \multicolumn{1}{c}{ Baseline } & \multicolumn{1}{c}{ Technology upgrade } & \multicolumn{1}{c}{ Method for implementation in EnergyPlus } \\
\hline No smart plugs & Smart plugs & $\begin{array}{l}\text { Applying 25\% saving to 100\% occupancy and 50\% distributed occupancy; } \\
\text { Applying 25\% saving to occupied zone in consolidated occupancy; } \\
\text { No saving for unoccupied zone due to unavailable literature or dataset }\end{array}$ \\
\hline Scheduled lighting & Occupancy-based lighting & $\begin{array}{l}\text { The lighting schedule follows occupancy schedules plus an extra 5\% for } \\
\text { safety at all times }\end{array}$ \\
\hline Standard scheduled setpoints & Occupancy-based thermostat schedule & Reducing setpoint to a constant $17^{\circ} \mathrm{C}$ in unoccupied zones \\
\hline No DCV & DCV & Activating DCV in EnergyPlus \\
\hline
\end{tabular}

over the $\mathrm{CO}_{2}$ concentration method since this study aims to quantify the potential of the technology, rather than on occupant sensing capabilities.

2.3.5 A summary of technologies and methods of implementation

Table 4 shows a summary of the base case model, technology upgrades proposed in the previous subsections, and the method of implementation in EnergyPlus.

\subsection{Energy comparison metrics}

Energy Use Intensity (EUI): Energy Use Intensity is defined as the energy use of a building divided by its total floor area 
in $\mathrm{kWh} / \mathrm{m}^{2} /$ year. EUI is reported for the total energy use of the building. In addition, it is also reported for electricity which includes lighting, space cooling, fans, and receptacle equipment, and gas for the boiler.

Energy Use per Person (EUP): Energy Use per Person is defined as the total energy use of the building $\left(E_{\text {total }}\right)$ divided by the sum of occupant-hours $\left(O c c_{\text {total }}\right)$ in the building (kWh/person-year) (Eq. (2)). This metric is used to facilitate the comparison among buildings (O’Brien et al. 2017). When there is a hoteling scenario in which occupancy can reach $100 \%$, energy can be normalized by the number of users, in which case the energy use per person would decrease further.

$\mathrm{EUP}=\frac{\sum E_{\text {total }}}{\sum O c c_{\text {total }}}$

GHG Emissions: GHG emissions are calculated based on the $\mathrm{CO}_{2}$ equivalent $\left(\mathrm{CO}_{2} \mathrm{e}\right)$ using the data from Natural Resources Canada for electricity and natural gas in each province of Canada for the total energy use by end-uses (i.e., electricity and natural gas) (Environment and Climate Change Canada 2018) (Table 5). Note that Canada has a large diversity of electricity sources from predominantly hydroelectric (Zone 4) and nuclear to predominantly fossilfuel-based (Zones 7A and 8).

\section{Results}

In this section, overall trends and results are first presented based on different technologies that were implemented in the building model. Each section reports on the technologies that were used for each scenario. GHG emissions are also reported at the end based on the GHG emission of each province in Canada. GHG emissions are separated based on their source since GHG emissions are reported for electricity and natural gas in each province. Then, the results are discussed in Section 4. To avoid complex terminology hereafter, $0 \%$ occupancy scenario is named as "Occ( $0 \%)$ ", $50 \%$ distributed as "Occ(50\%)", 50\% consolidated occupancy in the core zone as "OccCore(50\%)", 50\% consolidated occupancy in the perimeter zone as "OccPerim(50\%)", and full occupancy as "Occ(100\%)".

\subsection{Overall trends in base cases in different climates}

A comparison of energy end uses in base models shows unoccupied buildings ( $\%$ occupancy) consume more energy in climates with higher HDD (HDD > 6000) in comparison to warmer climates (Figure 9). In general, the energy use for $\operatorname{Occ}(100 \%)$ is higher in comparison to other scenarios. Overall, the results show that energy consumption increases

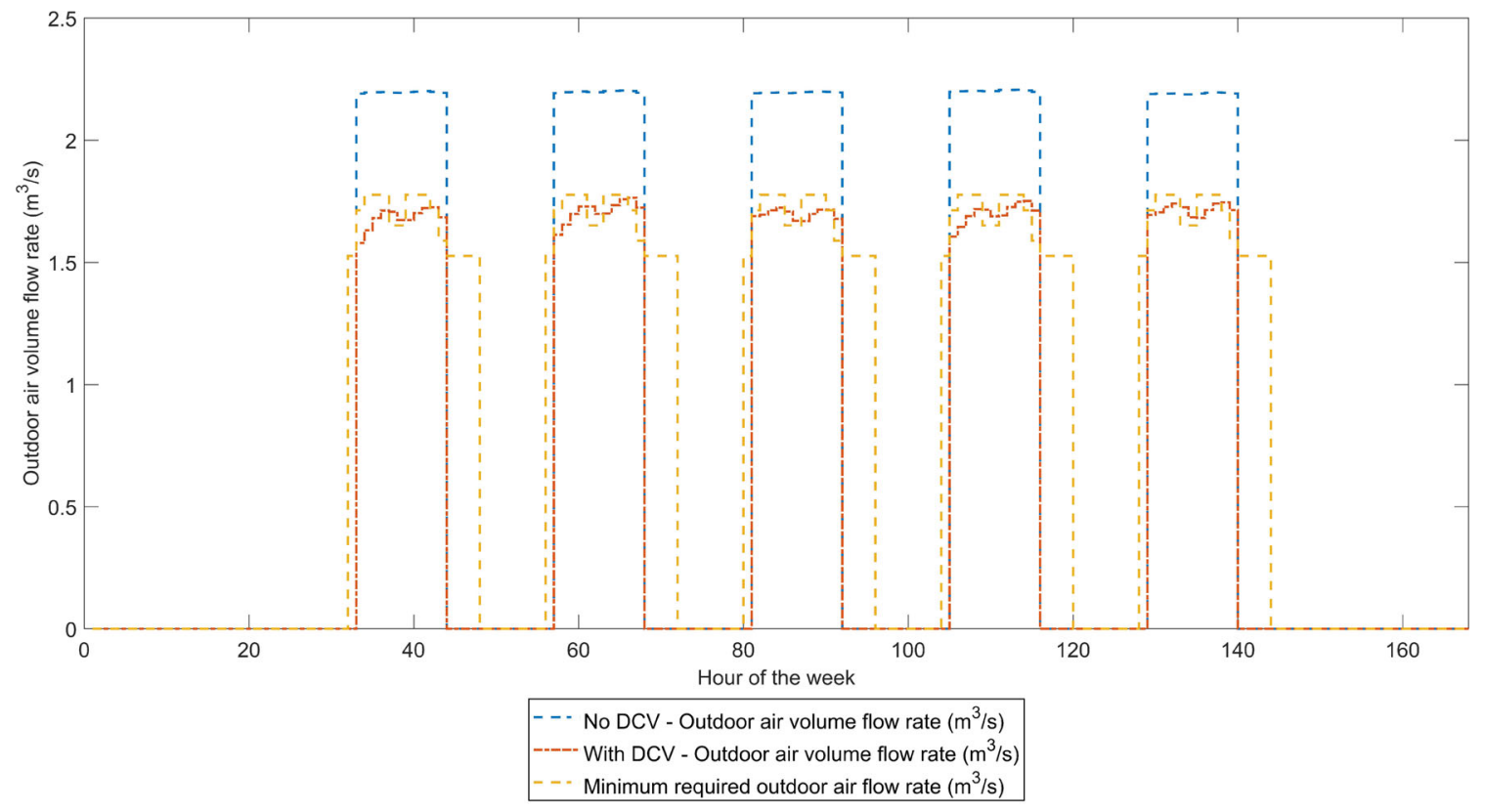

Fig. 8 A typical week with and without DCV

Table 5 GHG emissions of electricity and natural gas in each climate zone

\begin{tabular}{cccccccc}
\hline & Source & Zone 4 & Zone 5 & Zone 6 & Zone 7B & Zone 7A & Zone 8 \\
\hline \multirow{2}{*}{$\mathrm{CO}_{2} \mathrm{e}$} & Electricity (tonnes $/ \mathrm{kWh})$ & 0 & $0.040 \times 10^{-3}$ & $0.040 \times 10^{-3}$ & $0.052 \times 10^{-3}$ & $0.66 \times 10^{-3}$ & $0.44 \times 10^{-3}$ \\
\cline { 2 - 7 } & Natural gas $(\mathrm{kg} / \mathrm{GJ})$ & $63.29 \times 10^{-3}$ & $63.29 \times 10^{-3}$ & $63.29 \times 10^{-3}$ & $63.29 \times 10^{-3}$ & $63.29 \times 10^{-3}$ & $63.29 \times 10^{-3}$ \\
\hline
\end{tabular}



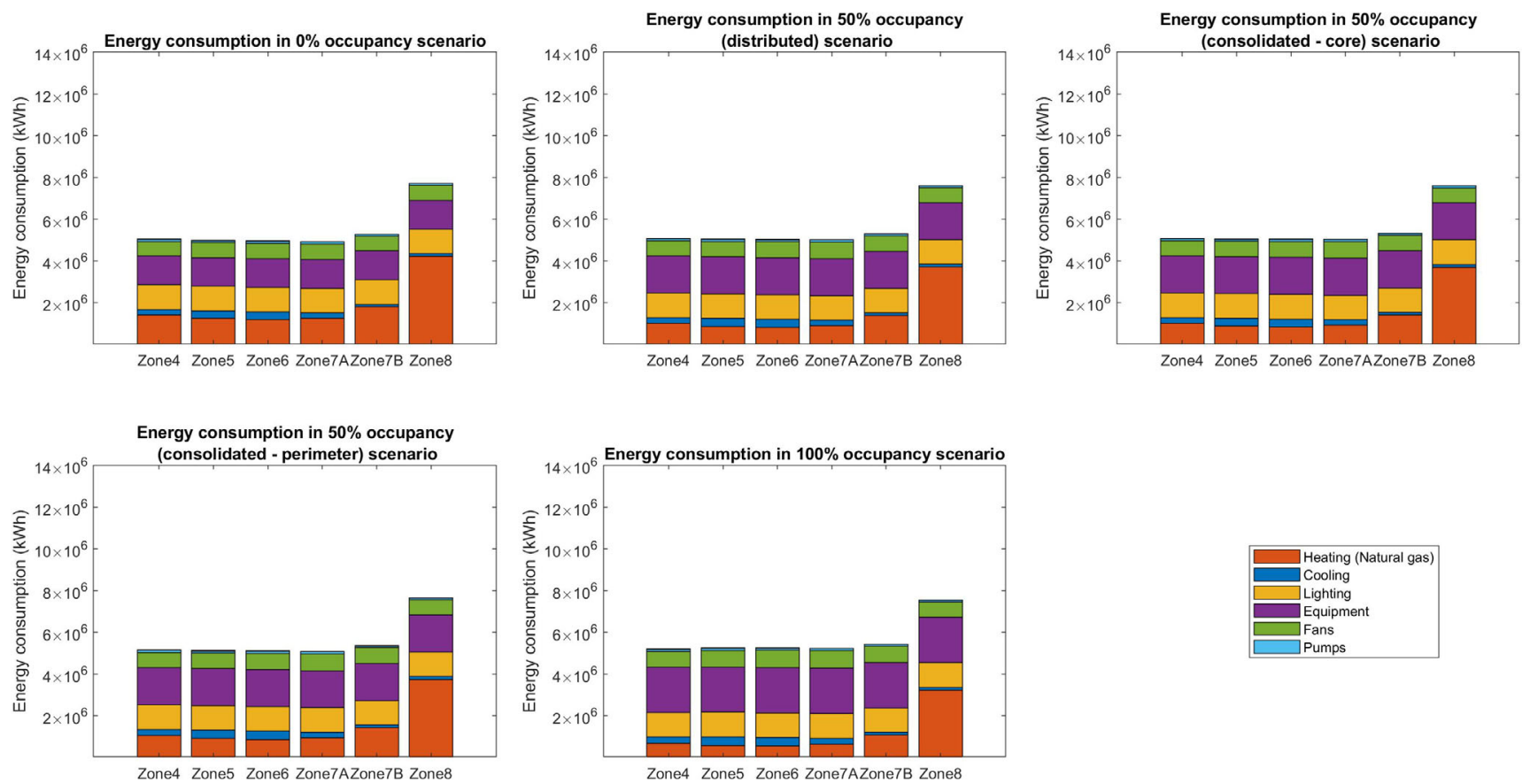

Fig. 9 Breakdown of major annual energy end uses by component in base cases; this figure shows the base cases are in accordance with ASHRAE's international benchmark [The results in this study follow the same pattern and overall proportion of different end-uses as ASHRAE's Zone 4 (Baltimore) to Zone 8 (Fairbanks)] (ASHRAE 2014)

from Zone 4 to Zone 8. Figure 9 illustrates that heating load is the dominant load in $0 \%$ occupancy which shows empty buildings need more energy for heating. Similarly, more energy is used for heating in partially occupied buildings. This shows that buildings are sensitive to occupancy and internal heat gains impact the heating and cooling loads significantly.

\subsection{The impact of occupancy-based lighting on EUI, EUP, and electricity usage}

First, total impacts are reviewed and then the following sections provide more detail on individual impacts. According to Figure 10, it is observed that the impact of occupancybased lighting is maximized under the $\mathrm{Occ}(0 \%)$. According to Figure 10 and Figure 11, the impact of occupancy-based lighting on EUI and EUP is higher in OccCore $(50 \%)$ while its impact is reduced in OccPerim(50\%) in terms of EUI and EUP, which is mostly due to changes in internal heat gains. It is obvious that this strategy does not affect the full occupancy building performance since all occupants are present.

The potential saving of occupancy-based lighting on overall EUI and EUP decreases as lighting comprises a smaller portion of the total EUI and EUP. Furthermore, it should be noted that the impact of occupancy-based lighting on the lighting electricity savings of the building is almost $84 \%$ in $\operatorname{Occ}(0 \%)$ while it is around $42 \%$ for $50 \%$ occupancy scenarios (Figure 12 shows a sample for Zone 4). In all cases, implementing occupancy-based lighting can save a significant amount of electricity. However, it should be noted that the potential savings are reduced in some scenarios in Zone 8 due to the impact on internal gains. Furthermore, occupancybased lighting resulted in an approximately $5 \%$ reduction in the $\operatorname{Occ}(0 \%)$ while is not affected in the $100 \%$ occupancy scenario in terms of EUI and EUP. The reason behind the latter is that the lights follow the original schedules for the $100 \%$ occupancy scenario since the building is operating in a full occupancy scenario.

3.3 The impact of occupancy-based plug load plus smart plugs on EUI and EUP

The results show that the maximum saving in this section is achieved during full occupancy since more occupants are present in the building during full occupancy in comparison to other occupancy scenarios (Figures 10 and 11). Figure 13 illustrates the potential savings for the electricity consumption of plug loads. The impact of occupancy-based plug load plus smart plugs on the EUI and EUP decreases as the HDD increases from Zone 4 to Zone 8 since the total energy use increases by almost $100 \%$.

\subsection{The impact of DCV on EUI and EUP}

Figures 10 and 11 indicate the impact of DCV on EUI and EUP increases in climates with higher HDD. For instance, in 

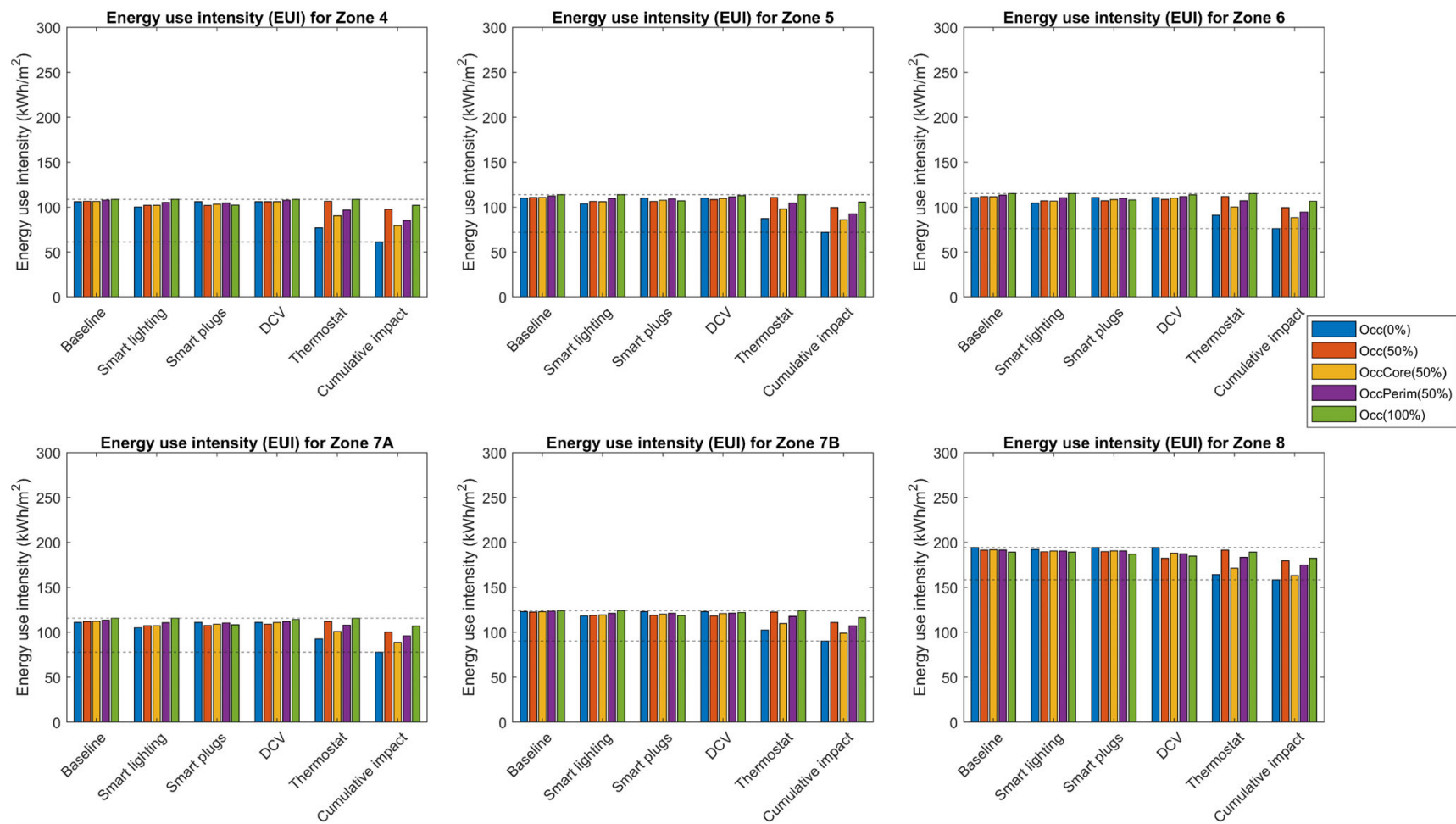

Fig. 10 Results for the impact of different technologies on the EUI in each climate zone; note that overall EUI is higher in colder climates. Also, the setpoint relaxation is not applied to Occ(50\%) and Occ(100\%)
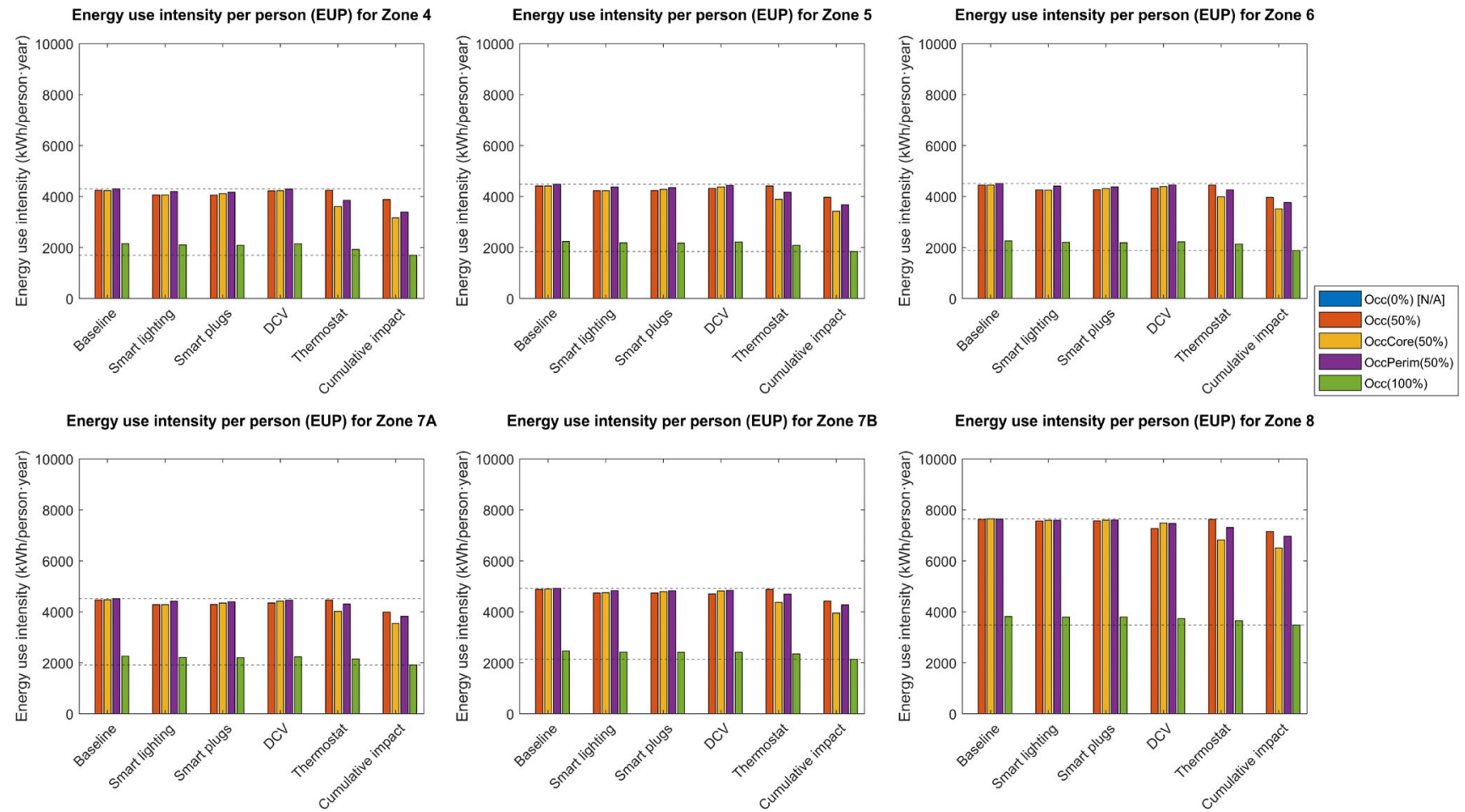

Energy use intensity per person (EUP) for Zone 8

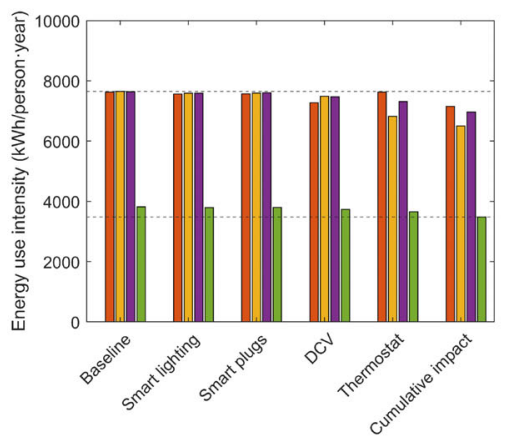

Fig. 11 Impact of different technologies on EUP in each climate zone; the results are normalized based on 250 people in Occ(100\%) and 125 people in $\operatorname{Occ}(50 \%)$. The results show the potential for saving energy by using strategies such as hot-desking for reducing EUP based on the total occupants. In this figure, $\operatorname{Occ}(0 \%)$ is not applicable since there is no occupant in the building 


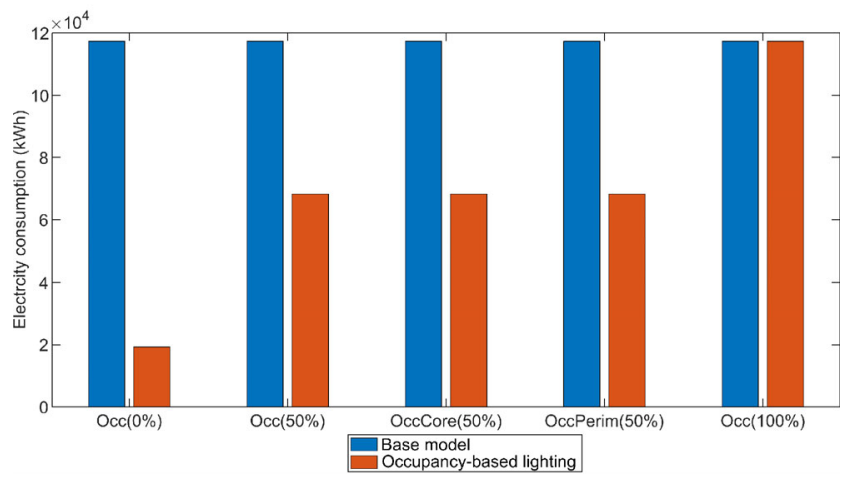

Fig. 12 Comparison of annual lighting electricity usage in Zone 4 before and after implementing occupancy-based lighting

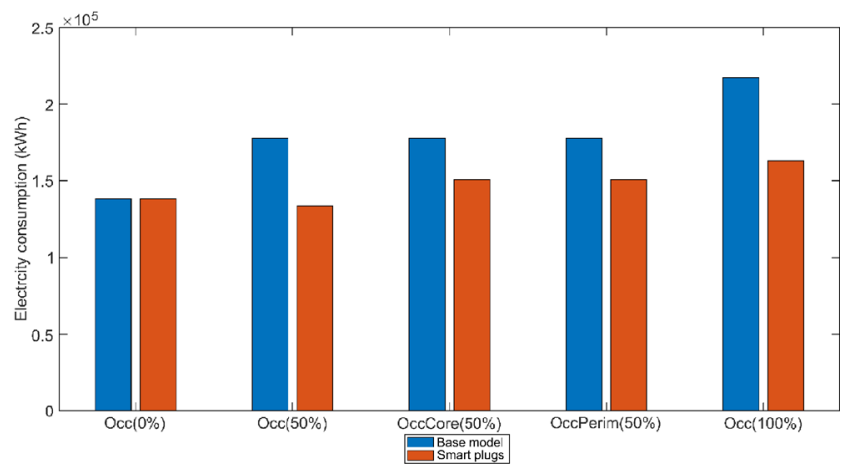

Fig. 13 Annual electricity consumption of plug loads and the savings from smart plugs; note that $\mathrm{Occ}(50 \%)$ is saving more energy than OccCore(50\%) and OccPerim(50\%). The reason is due to the fact that permanently empty zones (unoccupied) are not provided with potential savings due to the lack of evidence and potential normalized savings. The same applied to $\operatorname{Occ}(0 \%)$ this study, Zone 4, which is the climate with the lowest HDD, has a saving of $0.42 \%$ in $\mathrm{Occ}(50 \%)$ while Zone 8 , which is the climate with the highest HDD, has almost a saving of $5 \%$. The maximum saving is achieved in $\operatorname{Occ}(50 \%)$. The results show that the impact of DCV is necessarily tied with the climate zone and occupancy scenario. The saving potential is significantly higher in climate zones with higher HDD while its impact might be insignificant in climates with an HDD below 3000. Similarly, the maximum impact of implementing DCV is in the Occ (50\%) across all climate zones. It is obvious that implementing DCV will have no impact on $0 \%$ occupancy since no one is present in the building.

Figure 14 shows the detailed results of the impact of DCV on the fraction of outdoor air. By using DCV, the fraction of outdoor air is reduced on different floors. In the base model, the minimum fraction of outdoor air is higher in the second and third floors. (This was determined by EnergyPlus based on initial hard sizing in the base cases). The fraction drops in all cases by using the DCV. Figure 15 shows the outdoor airflow rate, calculated minimum required outdoor air by ASHRAE standard 62.1 (ASHRAE 2019b), and the status of the economizer. Accordingly, the economizer allows more outdoor air to enter the building in warmer seasons and this helps to reduce the cooling load of the building.

\subsection{The impact of occupancy-based thermostat schedules on EUI and EUP}

According to Figures 10 and 11, the thermostat strategy,
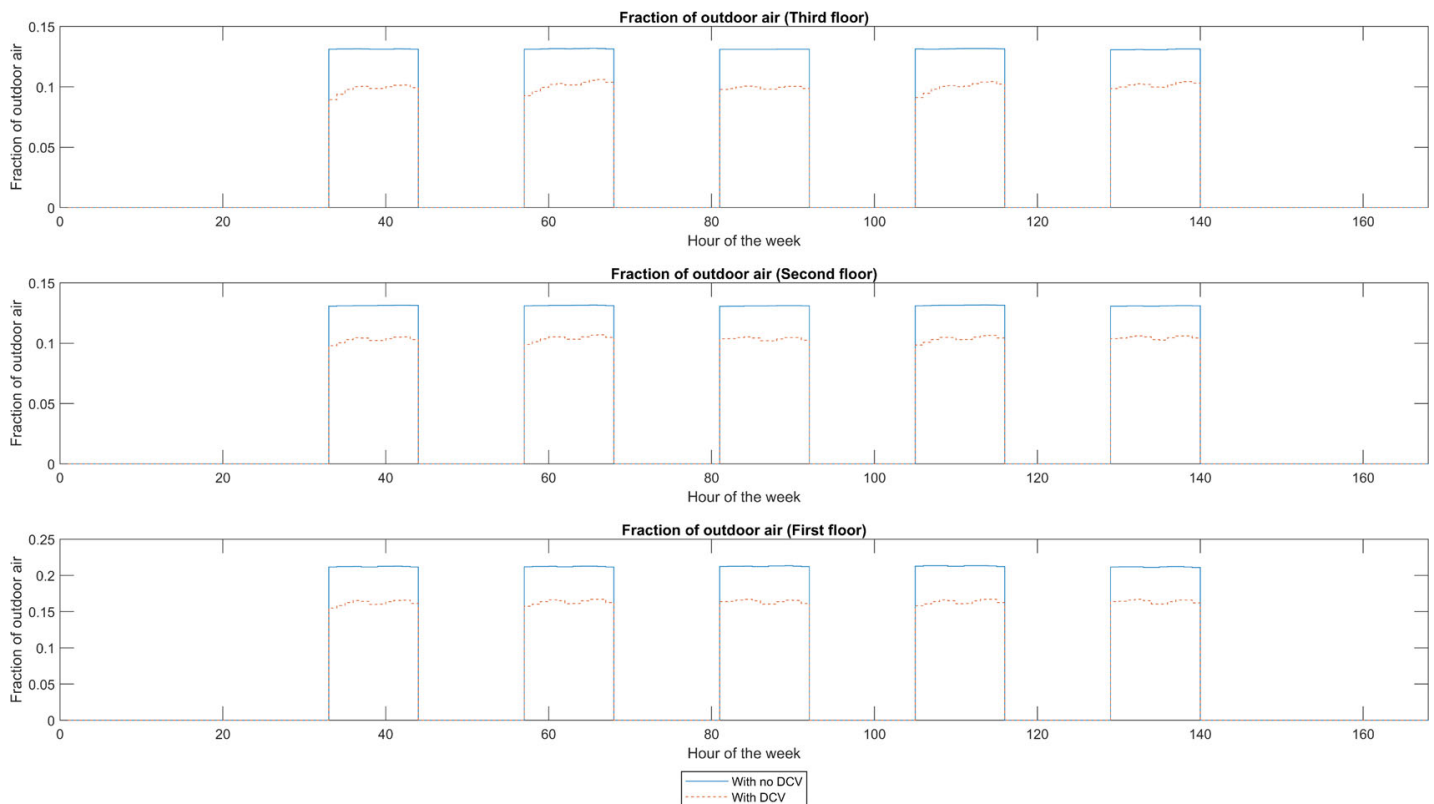

Fig. 14 Impact of DCV on the fraction of outdoor air in Zone 8; note that the fraction of outdoor air on the first floor is slightly higher than the other two floors. These values were determined by EnergyPlus during the hard-sizing period based on several different factors including minimum and maximum outdoor airflow rate. The difference here mainly relies on EnergyPlus calculation methods related to the differences between floors and the impact from exposure to outdoor and ground 


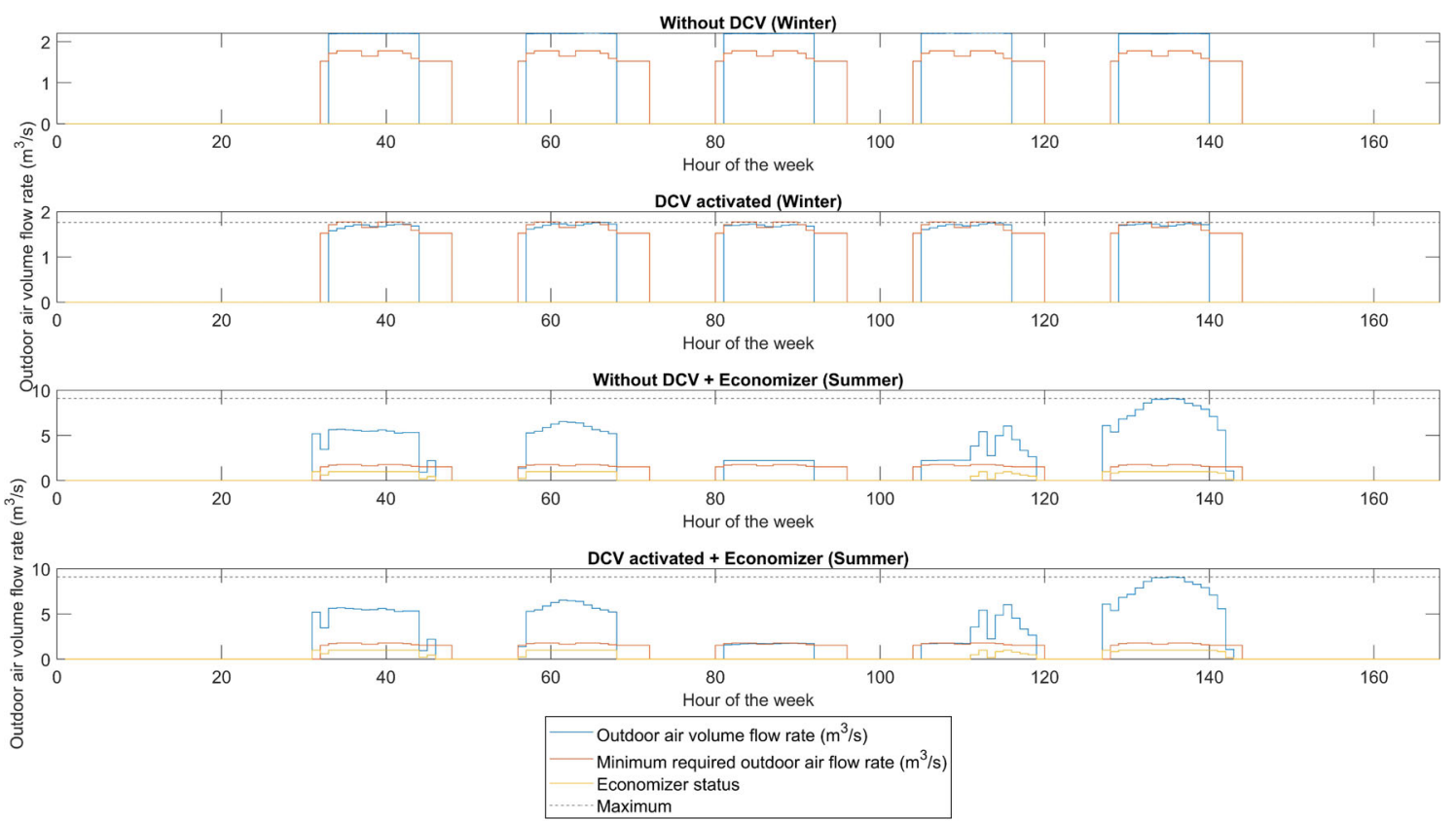

Fig. 15 A weekly sample comparison of outdoor air volume flow rate, minimum required outdoor air, and the economizer statues for Zone 8

which reduces the thermostat setpoint by $1^{\circ} \mathrm{C}\left(\right.$ to $\left.17^{\circ} \mathrm{C}\right)$ in permanently unoccupied zones, resulted in great savings in comparison to other strategies. The highest saving was achieved in the $0 \%$ occupancy in Zone 4 while it gradually decreased in the 5 other climate zones. These results show that this strategy has a reverse relationship with HDD in contrast to DCV which its saving increased in climates with higher HDD. This is due to the relative magnitude of $1^{\circ} \mathrm{C}$ compared to the difference between indoor and outdoor air temperatures in the heating season. Furthermore, the saving for OccCore(50\%) was higher than OccPerim(50\%) across all climate zones. It is obvious that this strategy was not implemented in Occ(50\%) and full occupancy scenario since occupants were present in the entire building (no permanently unoccupied zone). Figure 16 shows the annual heating coil gas usage for Zone 4 and mean indoor air temperatures.
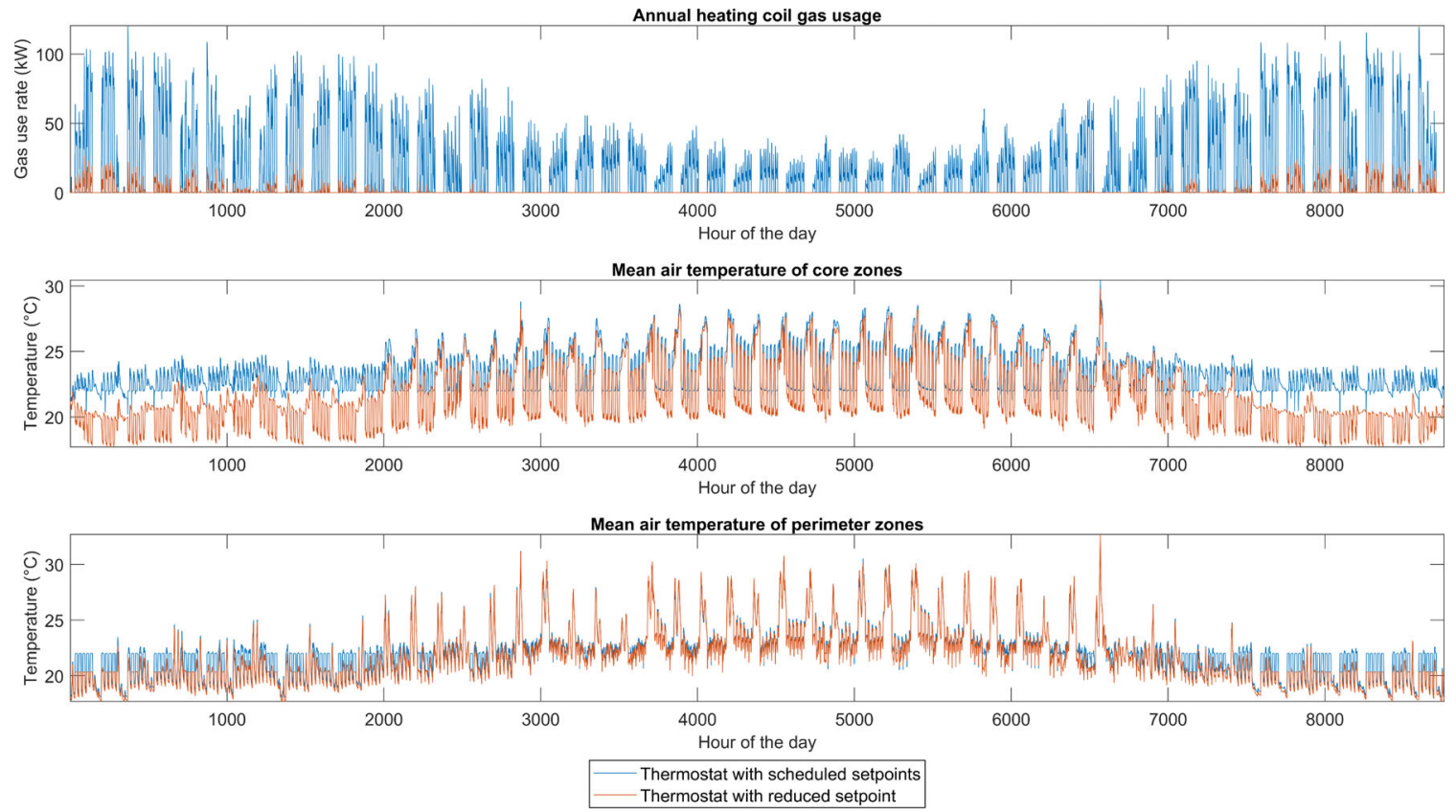

Fig. 16 Comparison of annual heating coil gas usage and mean air temperature in the core and perimeter zones for 0\% occupancy scenario in Zone 4 
Figure 17 illustrates that reducing the thermostat setpoint results in greater variation in indoor air temperature. As a result, this issue reduced the overall EUI and EUP of the building.

3.6 The impact of implementing all the technologies in offices on EUI and EUP

Similar to the impact of the occupancy-based thermostat, the potential savings of implementing all strategies in $0 \%$ occupancy reduces from Zone 4 to Zone 8 . In contrast, the energy savings in the full occupancy scenario increases from $5 \%$ in Zone 4 to approximately $7 \%$ in Zone 8 . Among all different types of $50 \%$ occupancy scenarios, the Occ $(50 \%)$ experienced the least savings while the OccCore(50\%) had the maximum saving. This is partially due to the fact that OccCore (50\%) had the most savings from the occupancybased thermostat and DCV strategies.

The cumulative effect of all strategies illustrates both OccCore (50\%) and OccPerim(50\%) save significantly more energy in comparison to $\operatorname{Occ}(50 \%)$. Between the two scenarios of $50 \%$ consolidated occupancy, OccCore(50\%) saves more energy in comparison to OccPerim(50\%). Therefore, it can be concluded that working in core zones is more energyefficient than other occupancy scenarios when the building is partially occupied. However, the opposite, where occupants work in the perimeter zones, offers benefits beyond energy efficiency such as outdoor views. Furthermore, the Occ(0\%) had the most saving in this study while the lowest saving was in the $\operatorname{Occ}(100 \%)$. In addition, the relationship between all strategies and HDD was negative except for $100 \%$ occupancy. Figure 18 summarizes the potential saving of each strategy in different climates and occupancy scenarios.

\subsection{GHG emissions for different scenarios}

GHG emissions are discussed in two separate sections for electricity and natural gas due to significant differences in values.

\subsubsection{GHG emissions for electricity}

Overall, the lighting and plug loads are two primary sources of electricity consumption. Accordingly, saving is significant for these two strategies. The reduction in $\mathrm{CO}_{2} \mathrm{e}$ for lighting is significant in the $\operatorname{Occ}(0 \%)$ and fluctuates in different climates (Figure 19). There are also significant savings in $50 \%$ occupancy scenarios. In general, it can be concluded that the $\mathrm{CO}_{2}$ e reduction for lighting is directly connected to climate zones since higher HDDs result in better savings. Similarly, the potential savings for occupancy-based plug loads and smart plugs increase in colder climates. However, the savings are higher for Occ(50\%) scenario among all 50\% occupancy scenarios (Figure 19). On the other hand, the full occupancy scenario has the highest saving for smart plugs in all climate zones. It should be noted that the significant differences are due to differences in associated GHG emissions for electricity in each province of Canada.
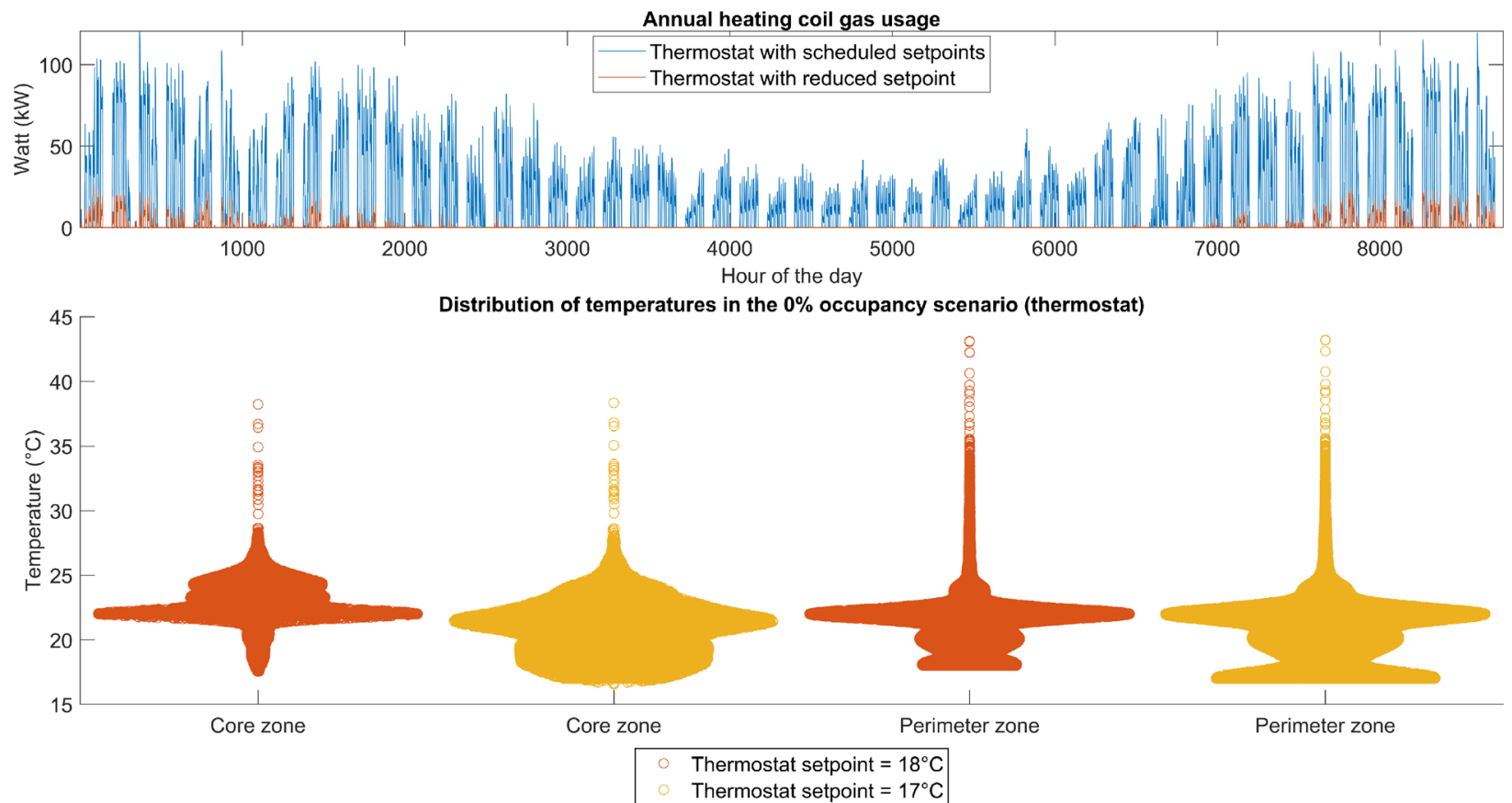

Fig. 17 Comparison of the impact of reduced thermostat setpoints on the distribution of indoor air temperatures in the $0 \%$ occupancy scenario in Zone 4; note the differences between the distribution of indoor air temperature in different building zones that results in reduced load on the heating system. The results for annual indoor air temperature and are not narrowed down to cold months 


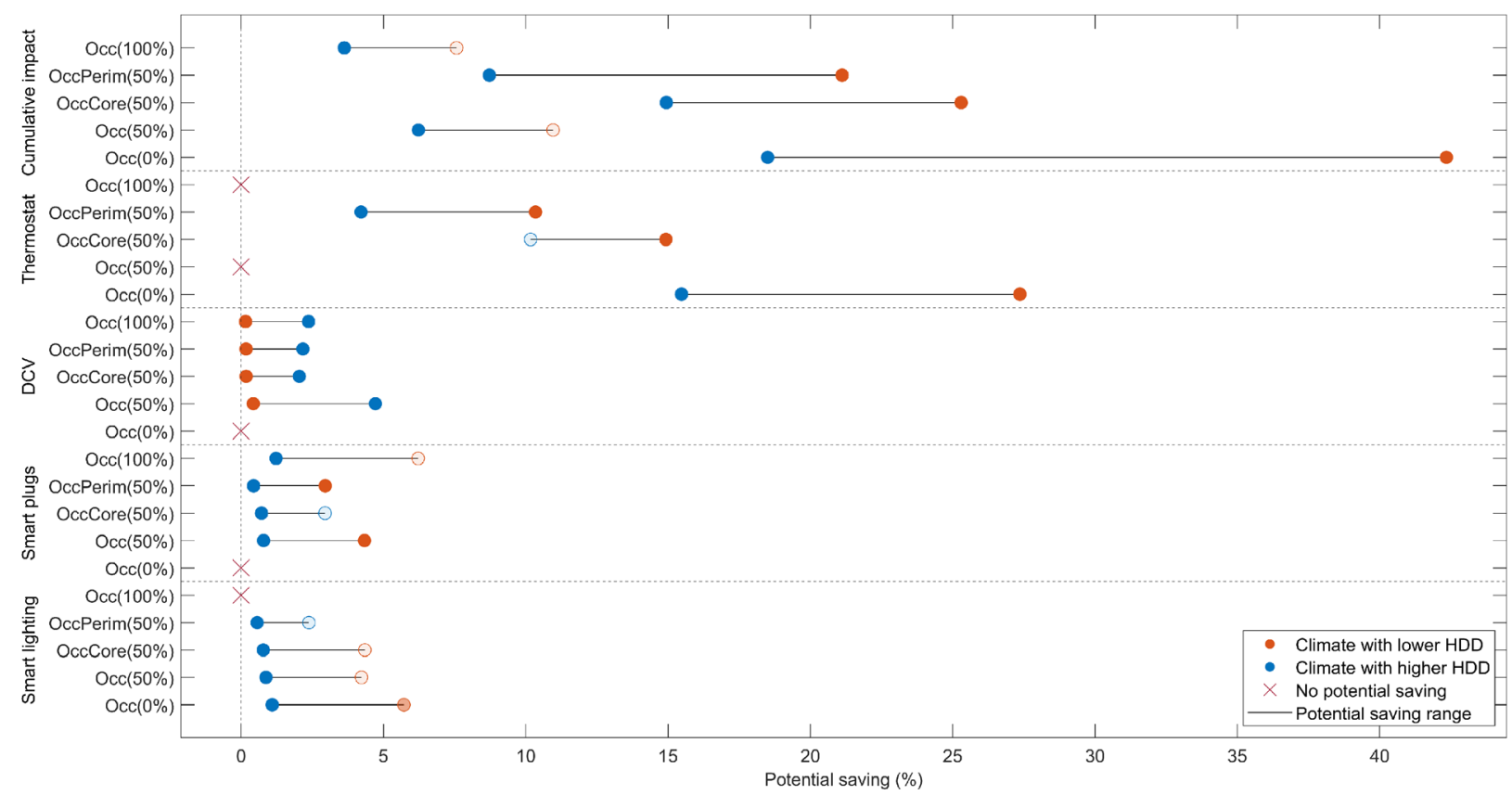

Fig. 18 The range of savings for each technology in different scenarios and climates; darker transparent circles show the maximum saving occurs in Zones 5 and $7 \mathrm{~B}$ rather than Zone 4 or 8 (e.g., Occ( $0 \%)$ in smart lighting is Zone 5) and lighter transparent circles show the maximum saving occurs in Zones 6 and 7A (e.g., $\operatorname{Occ}(50 \%)$ in smart lighting is Zone 6)
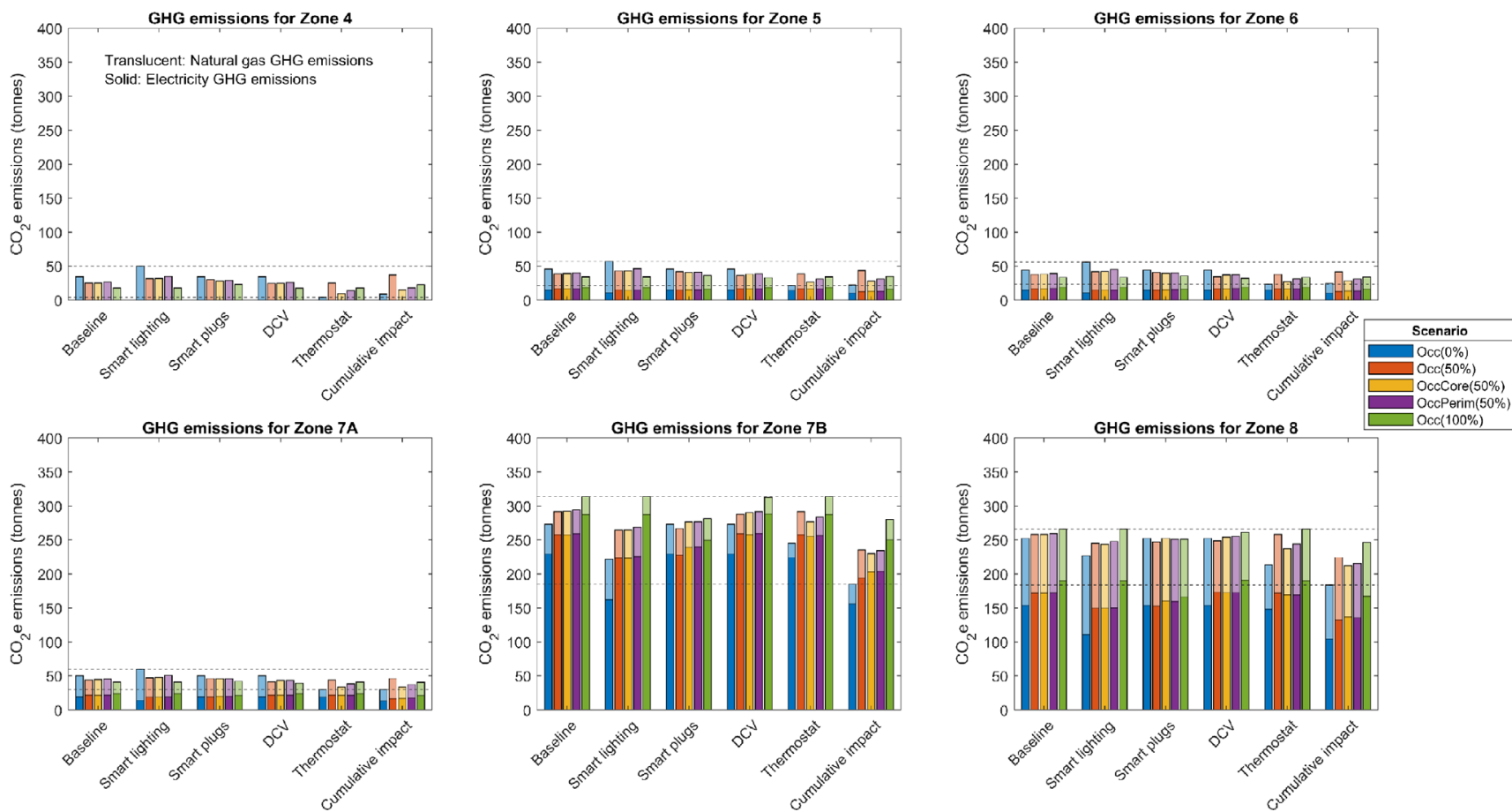

Fig. $19 \mathrm{CO}_{2}$ e for electricity and natural gas in Zones 4 to 8 . As noted in the methodology section, the $\mathrm{CO}_{2} \mathrm{e}$ for electricity is zero in the province of British Columbia (Zone 4) which is represented by Vancouver in this study

Moreover, the impact of DCV is insignificant and normally has an adverse effect in terms of GHG emissions for electricity that is caused by nuances of electricity used for pumps and cooling. Additionally, the present results suggest that the impact of changing the thermostat setpoint in unoccupied zones is nominal for most of the zones except Zones $7 \mathrm{~B}$ and 8 that (savings around 1\%). While the impact of different strategies on $\mathrm{CO}_{2} \mathrm{e}$ emissions depends on the climate zones and technologies themselves, these strategies all together yield significant savings in terms of $\mathrm{CO}_{2} \mathrm{e}$. 


\subsubsection{GHG emissions for natural gas}

The $\mathrm{CO}_{2} \mathrm{e}$ for natural gas is presented in this section. According to Figure 19, the overall trends show that the $\mathrm{CO}_{2} \mathrm{e}$ for natural gas increases when occupancy-based lighting is implemented. This is due to partial occupancy which results in a reduced internal heat gain and increased heating loads for the building. Regarding the occupancy-based lighting, it can be observed that the maximum increase in the $\mathrm{CO}_{2} \mathrm{e}$ occurs in the $\mathrm{Occ}(0 \%)$. In general, $\mathrm{CO}_{2} \mathrm{e}$ there cannot be a conclusive verdict for the relationship between the impact of climate and scenario on $\mathrm{CO}_{2} \mathrm{e}$ although $\mathrm{CO}_{2} \mathrm{e}$ for natural gas increases from warmer climates to colder climates.

In contrast, the maximum increase in $\mathrm{CO}_{2} \mathrm{e}$ in occupancy scenarios with occupancy-based plug load and smart plugs occurs in full occupancy scenario while there was no impact in the $0 \%$ occupancy. An overall trend for $\mathrm{Occ}(50 \%)$ is increasing $\mathrm{CO}_{2} \mathrm{e}$ for cumulative impact and decreasing $\mathrm{CO}_{2} \mathrm{e}$ for OccPerim(50\%) and OccCore(50\%).

While both occupancy-based lighting and occupancybased plug loads along with smart plugs had an adverse effect on GHG emissions, implementing DCV showed favorable results and savings greater than the increases in the previous two strategies. Accordingly, implementing DCV is very effective in Occ(50\%). From Figure 19, it can be concluded that the impact of DCV on GHG emissions is higher in colder climates. Furthermore, Figure 19 shows that the reduction in $\mathrm{CO}_{2} \mathrm{e}$ is higher in $50 \%$ occupancy scenarios which are similar to the findings on the EUI and EUP.

Although implementing DCV shows promising results, the most effective strategy in reducing the $\mathrm{CO}_{2} \mathrm{e}$ was reducing the setpoint of thermostats by $1{ }^{\circ} \mathrm{C}$ in unoccupied zones in $50 \%$ occupancy scenarios. The overall trend for $50 \%$ consolidated occupancy shows that the savings are higher in OccCore(50\%).

\section{Discussion}

In this section, comparisons are made between the current study and previous studies on partial occupancy and office buildings whenever such literature is available (the literature on partial occupancy is scarce). Furthermore, major findings, important issues, and underlying reasons for various technologies are discussed.

4.1 The potential savings of occupancy-based lighting and smart plugs

While this study showed potential savings in different scenarios by using occupancy-based lighting, an important finding is evaluating the impact of this technology during the $50 \%$ occupancy scenarios. The results showed potential savings are higher in the OccCore $(50 \%)$ in terms of the EUI and EUP, especially in colder climates. However, the difference between OccCore(50\%) and Occ(50\%) is negligible. The importance of occupancy-based lighting in contrast to standard schedules was documented elaborately previously (O’Brien and Gunay 2019). A previous study with rigid lighting control showed about a $40 \%$ reduction in electricity usage when using occupancy-based lighting control (Rubinstein and Enscoe 2010) which is in agreement with the findings of this study (Figure 12). The results show occupancy-based lighting in partial occupancy scenarios saves almost the same amount as other strategies do during full occupancy such as dimming strategies with high-resolution occupancy data (Lowcay et al. 2020).

In contrast, the impact of smart plugs on EUI was higher in Occ(50\%) in comparison to the OccPerim(50\%) and OccCore(50\%). This shows that the internal gains from plug load are more significant than lighting. As a result, the EUI is lower than OccCore(50\%) and OccPerim(50\%), respectively. It should be noted that the EUI is higher in $0 \%$ occupancy since no one is present in the building and internal gains from plug loads are minimal.

The present study showed smart plugs are generally an effective solution to save energy. For instance, the evidencebased approach (Metzger et al. 2012) shows these smart plugs can detect which devices of the master outlet need power and adjusting thresholds accordingly and thus, saving energy in different occupancy scenarios. Such smart plugs can save more energy by regulating electricity distribution even during occupancy hours. Although the savings for electricity are significant when these technologies are used, their overall impact on EUI and EUP is different. Furthermore, the results show that there is a negative relationship between these two strategies and HDD meaning that the potential savings are reduced as the HDD increases in different climates. Suggestions are made in Section 4.4 on when and where to use which technology. Furthermore, these two technologies should be used with caution in extreme climates (HDD > 8000) since EUI and EUP as well as GHG emissions can increase slightly in such climates. The underlying issue is the decreased internal gains in such climates.

\subsection{The relationship between DCV and HDD and its potential savings}

The results of this study suggest implementing DCV in colder climate zones results in significant savings while its impact in climates with lower HDD might be less significant. Furthermore, the results of this study confirmed the findings of previous studies that demonstrated DCV yields higher savings under partial occupancy rather than full occupancy 
(Jemaa et al. 2018; Abuimara et al. 2019; O’Brien and Gunay 2019). These findings illustrate there is a direct relationship between potential savings that resulted from DCV and increasing HDD. Moreover, our study on types of distribution shows that $\operatorname{Occ}(50 \%)$ had the most savings but it should be noted that the base case EUI and EUP are also lower in the $\operatorname{Occ}(50 \%)$.

4.3 The relationship between occupancy-based thermostat and HDD and its potential saving

Similar to occupancy-based lighting, the occupancy-based thermostat is more effective in OccCore $(50 \%)$ than OccPerim(50\%). This is obvious that the potential savings for this strategy are at most in the $\mathrm{Occ}(0 \%)$ since the thermostat setpoint is reduced by $1^{\circ} \mathrm{C}$ in the entire building. Furthermore, the relationship between the occupancy-based thermostat and HDD is negative meaning that the potential savings by this strategy reduce as HDD increases.

The findings of this study are consistent with previous studies on occupancy-based thermostat setpoints although this paper could not find any previous study on thermostat setpoints and partial occupancy in office buildings. A previous simulation-based study based on 463 field data showed that increasing the cooling setpoint by $2^{\circ} \mathrm{C}$ can result in $10 \%$ savings (Azar et al. 2021). Another study on libraries showed that the thermostat setpoint has a key role in reducing energy consumption (Al-Saadi et al. 2017). The results of the current study suggest significant savings are possible during partial occupancy if proper strategies, such as working in either core zones or perimeter zones, are used.
4.4 Ranking the promising strategies based on their savings

Figure 20 shows the conclusion of 180 simulations that were carried out for five occupancy scenarios. Accordingly, the occupancy-based thermostat and occupancy-based lighting saved the most energy in $\operatorname{Occ}(0 \%)$. The savings for occupancybased lighting is significant in warmer climates and moderate for colder climates due to reducing internal heat gains in warmer climates. However, it might not be an effective strategy for zones with higher HDD (HDD > 7000). Overall, it can be concluded that this strategy has a moderate potential for saving energy in zones with HDD less than 7000. In addition, it should be mentioned that this strategy works well in warmer climates (negative relationship).

Occupancy-based plug loads and smart plugs almost have the same effect. They have a moderate impact for Zones with HDD less than 6000 in Occ(50\%) and OccCore(50\%). The impact is also moderate in zones with HDD less than 7000 in OccPerim(50\%) and Occ(100\%). This strategy is more efficient in warmer climates (negative relationship). A less costly alternative to this is ensuring computers, printers, etc. are set to go in sleep mode after a certain period of inactivity.

The results of this study show the impact of DCV is low in zones with HDD less than 3000 while its impact is significant in $\operatorname{Occ}(50 \%)$ in climates with HDD higher than 6000. The impact is significant for all other occupancy scenarios in climate zones with HDD higher than 7000. These results demonstrate DCV is an appropriate choice for many climate zones and it is more efficient in colder climates (positive relationship) where increasing HDD results in more savings.

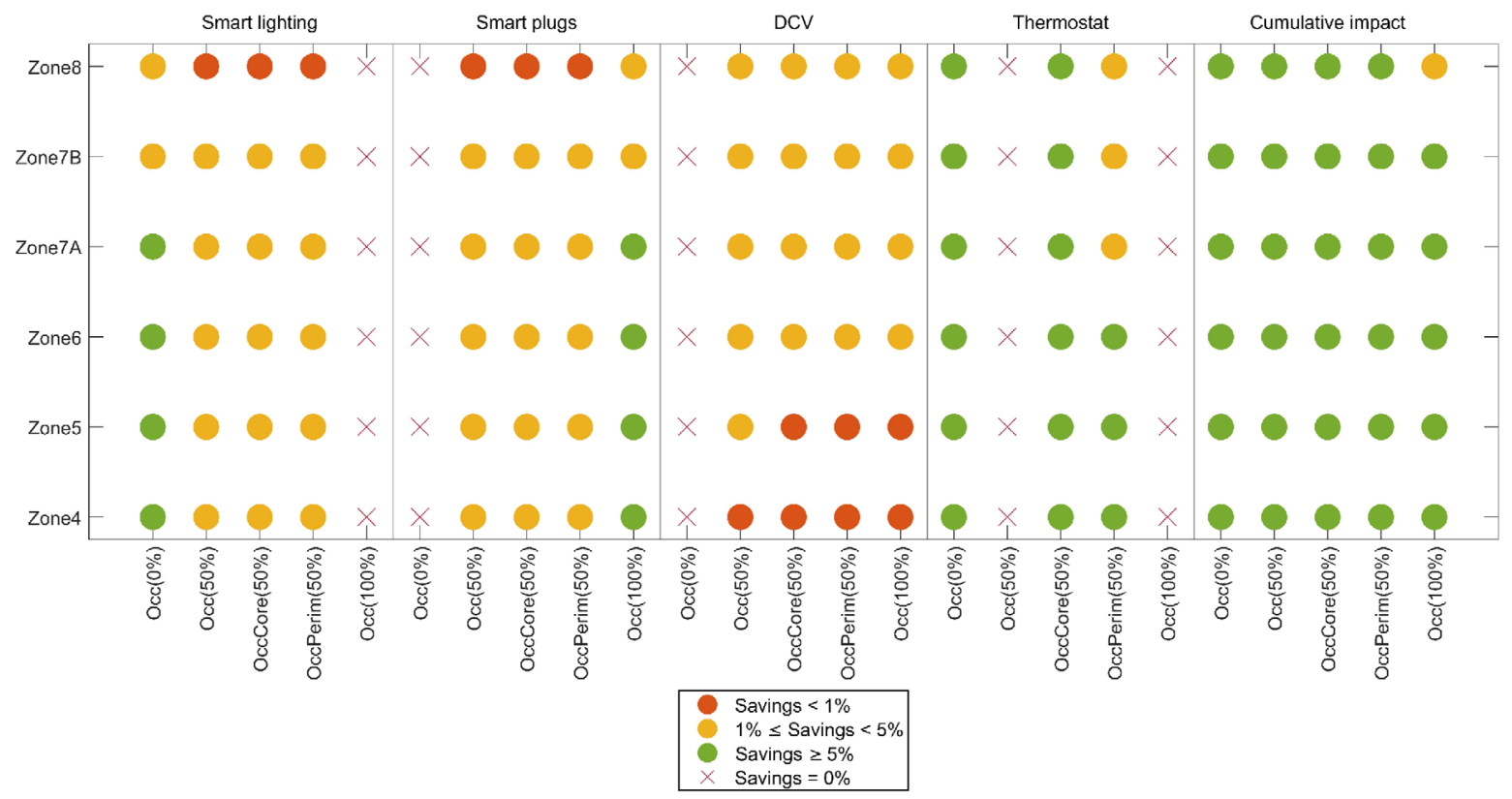

Fig. 20 Potential saving for each occupancy scenario and climate zone 
Although occupancy-based thermostat has limited applicability, it is the most efficient strategy for reducing the EUI and EUP when buildings are partially occupied in all climate zones. This strategy is highly recommended and should be the first choice when it can be implemented. The relationship between this strategy and HDD is negative which means increasing HDD results in lower savings.

The cumulative effect of all these technologies being implemented in buildings is significant although the relationship is negative which means increasing HDD results in lower savings. The results show that the savings can range from approximately $45 \%$ to $5 \%$ in different occupancy scenarios and climates.

The results of this study show that when buildings are partially occupied, the best strategy is to accommodate them in core zones regardless of the climate zones although the opposite, where occupants work in the perimeter zones, offers benefits beyond energy efficiency such as appealing views of outdoor. Therefore, it can be concluded that working in half of the building, either in perimeter zones or core zones or in any half of the building, is the optimal solution when buildings are partially occupied. The benefits of these strategies were well documented in this paper. The worst-case in partial occupancy is to accommodate occupants uniformly across the building. However, we acknowledge that distributed occupancy has the benefits of reduced air contaminants and noise.

GHG emissions also follow the EUI and EUP but there cannot be a conclusion on its values in different climate zones since each province in Canada has its own $\mathrm{CO}_{2} \mathrm{e}$. In other words, $\mathrm{CO}_{2} \mathrm{e}$ for electricity or natural gas can vary location by location and there cannot be an exact comparison between locations or climate zones. However, there was a relationship between GHG emissions and climate zones similar to those in EUI and EUP. Furthermore, it should be noted that a decrease in electricity might result in an increase in using natural gas for heating buildings. Although this study showed the cumulative effect of all these technologies saves energy, there might be instances in severe climates where GHG emissions from one source of energy offset the other. As a result, this issue requires a case-by-case analysis.

Overall, the results demonstrate performance adaptability of office buildings can improve during partial occupancy by implementing the studied technologies. Although the present study shows implementing these technologies and strategies can reduce the EUI, EUP, and GHG emissions, empty office buildings will still use a lot of energy. This was empirically shown according to Hatch Data, which are more than 50 million $\mathrm{m}^{2}$ of commercial buildings (Mendelson 2020). The COVID-19 pandemic has shown that electricity keeps running as scheduled in buildings and HVAC systems continue their operation during unoccupied days. Aside from these other components of buildings such as water heaters work almost 24/7 (Deaton 2020). There are also some operational limitations. For instance, the HVAC system cannot necessarily be shut down during unoccupied periods because of the vulnerability of pipes and the inability of the HVAC system to bring the building back up/down to temperature in time for occupancy. These issues show that no matter what measures and strategies we have in place, office buildings will still consume a lot of energy although the impact can be mitigated by using the technologies and strategies that this paper presented.

\section{Conclusions}

The aim of this study was to assess the energy impact of building adaptability to partial occupancy under five different occupancy scenarios and to investigate the impact of four technologies that can improve the building adaptability to partial occupancy. To achieve this, 30 simulations for six Canadian climates, which were categorized based on their HDD, were carried out that resulted in a total of 180 simulations. To address the lack of research on building performance under partial occupancy, the current study presented a comprehensive simulation-based investigation of how different technologies work under different occupancy scenarios in different climates for the first time systematically. Furthermore, the present study also demonstrated the results of how each technology saves energy in different occupancy scenarios and climates as a practical framework for designers, engineers, and developers.

The results suggest that office buildings use more energy during partial occupancy in base cases (RQ1 - occupancy impact). To summarize, the simulations of this study demonstrated that the various strategies have significantly different impacts on EUI, EUP, and subsequently, GHG emissions. According to the results, changing thermostat setpoints is the most efficient solution for reducing EUI and EUP in buildings when such a strategy can be implemented (RQ3 - distribution impact/technology impact). This strategy alone reduced EUI by $30 \%$ when the building is not occupied. Another major finding of this study showed that accommodating occupants in core zones is much more energy-efficient than accommodating occupants in perimeter zones or accommodating them uniformly across the floor (RQ2 distribution impact). Therefore, working in half of the buildings is an optimal solution during partial occupancy. The results also suggest occupancy-based lighting and occupancy-based plug loads along with smart plugs are significantly effective in warmer climates in most cases (RQ3 - distribution impact/technology impact). Overall, the present study showed that implementing all technologies together results in significant reductions in EUI, EUP, 
and GHG emissions while the impact of applying these technologies individually ranged from low to significant in different climate zones. Therefore, office buildings can adapt better to partial occupancy by using these technologies (RQ4 - adaptability). Furthermore, this paper showed that applying these technologies not only affects the EUI and EUP directly but also affects them indirectly through other measures such as internal gains. Accordingly, this study showed that only the relationship between HDD and DCV is positive while the relationship between HDD and all other technologies was negative, meaning that higher HDDs reduce the potential savings from these technologies.

The results of this study are for Canadian buildings where HVAC is often necessary to run, even when unoccupied. Canadian extreme climates represent the lower end of the potential for occupant-adaptive technologies. Even between the climates studied in this paper, it is obvious that colder climates mean less savings. But the savings would be much higher in locations like San Francisco, with mild temperatures year-round. Furthermore, within the scope of this paper, buildings are considered to be fully operational for full occupancy periods if needed but HVAC sizing can play a significant role in arrangements such as hot-desking. Some limitations are associated with this study that should be addressed in future studies by conducting field surveys. The primary limitation of this study was the use of big data for measuring the impact of smart plugs. Future studies should try to extract such information from a building under consideration for simulations. The second limitation was considering a linear relationship between lighting schedules and occupancy schedules. Furthermore, occupant behavior, including the control over operable window and shading system operation is not considered in the study. Future studies should investigate this issue in both simulations and field studies that focus on occupant behavior simultaneously. The final limitation of this study was assuming equal floor area for core zone and perimeter zones while this might not be the case for many offices in the world.

\section{Acknowledgements}

The authors would like to acknowledge the generous support of the Natural Sciences and Engineering Research Council of Canada (NSERC), Brookfield Global Integrated Solutions (BGIS) Canada LP, Ontario Centre of Innovation (OCI), Canada.

\section{References}

Abuimara T, Gunay B, O’Brien W (2019). Simulating the impact of occupants on office building design: A case study. In: Proceedings of the 16th IBPSA International Conference and Exhibition, Rome, Italy.
Abushakra B, Haberl JS, Claridge DE (2004). Overview of existing literature on diversity factors and schedules for energy and cooling load calculations. ASHRAE Transactions, 110(1): 164-176.

Afroz Z, Hobson BW, Gunay HB, et al. (2020). How occupants affect building operators' decision-making. ASHRAE Journal, 62(11): $22-30$.

Allen TD, Golden TD, Shockley KM (2015). How effective is telecommuting? Assessing the status of our scientific findings. Psychological Science in the Public Interest, 16: 40-68.

Al-Saadi SNJ, Ramaswamy M, Al-Rashdi H, et al. (2017). Energy management strategies for a governmental building in Oman. Energy Procedia, 141: 206-210.

ASHRAE (2014). Advanced Energy Design Guide for Small to Medium Office Buildings. Atlanta: American Society of Heating, Refrigerating and Air-Conditioning Engineers.

ASHRAE (2019a). Standard 90.1-2019. Energy Standard for Buildings except Low Rise Residential Buildings. Atlanta: American Society of Heating, Refrigerating and Air-Conditioning Engineers.

ASHRAE (2019b). Standard 62.1-2019. Ventilation for Acceptable Indoor Air Quality. Atlanta: American Society of Heating, Refrigerating and Air-Conditioning Engineers.

Azar E, Alaifan B, Lin M, et al. (2021). Drivers of energy consumption in Kuwaiti buildings: Insights from a hybrid statistical and building performance simulation approach. Energy Policy, 150: 112154.

BBC (2020). Coronavirus: How the World of Work May Change Forever. The British Broadcasting Corporation (BBC).

NRCan (2017). National Energy Code of Canada for Buildings (NECB). Canadian Commission on Building and Fire Codes and National Research Council of Canada.

Chen D, Chen HW (2013). Using the Köppen classification to quantify climate variation and change: An example for 1901-2010. Environmental Development, 6: 69-79.

Deaton J (2020). Empty office buildings are still devouring energy. Why? DOE (2020). EnergyPlus ${ }^{\mathrm{TM}}$. The U.S. Department of Energy's (DOE) Building Technologies Office. Available at https:/energyplus.net/ downloads.

Doherty B, Trenbath K (2019). Device-level plug load disaggregation in a zero energy office building and opportunities for energy savings. Energy and Buildings, 204: 109480.

Elldér E (2017). Does telework weaken urban structure-travel relationships? Journal of Transport and Land Use, 10: 187-210.

Environment and Climate Change Canada (2018). Lifecycle analysis (LCA) report. Environment and Climate Change Canada, Strategic Policy Branch, Economic Analysis Directorate, Analysis and Modelling Division.

Ghosh A, Patil KA, Vuppala SK (2013). PLEMS: Plug load energy management solution for enterprises. In: Proceedings of the IEEE 27th International Conference on Advanced Information Networking and Applications (AINA), Barcelona, Spain.

Graizbord B (2015). Teleworking as a mobility strategy for Mexico city. International Planning Studies, 20: 112-130.

Gunay HB, O’Brien W, Beausoleil-Morrison I, et al. (2016). Modeling plug-in equipment load patterns in private office spaces. Energy and Buildings, 121: 234-249. 
Hafer M, Howley W, Chang M, et al. (2017). Occupant engagement leads to substantial energy savings for plug loads. In: Proceedings of the IEEE Conference on Technologies for Sustainability (SusTech), Phoenix, AZ, USA.

Jemaa KB, Kotman P, Graichen K (2018). Model-based potential analysis of demand-controlled ventilation in buildings. IFAC-PapersOnLine, 51: 85-90.

Jenkins C, Young R, Tsau J, et al. (2019). Effective management of plug loads in commercial buildings with occupant engagement and centralized controls. Energy and Buildings, 201: 194-201.

John St J (2020). Why empty office buildings still consume lots of power during a global pandemic.

Katz S (2020). COVID-19 and building performance: The big picture.

Lowcay D, Gunay HB, O’Brien W (2020). Simulating energy savings potential with high-resolution daylight and occupancy sensing in open-plan offices. Journal of Building Performance Simulation, 13: 606-619.

Mazzeo D, Matera N, de Luca P, et al. (2020). Worldwide geographical mapping and optimization of stand-alone and grid-connected hybrid renewable system techno-economic performance across Köppen-Geiger climates. Applied Energy, 276: 115507.

Meier A (2020). Saving energy in buildings when nobody is in them.

Mendelson B (2020). Trends in energy use during COVID-19 indicate opportunity for value creation.

Mercier C, and Moorefield L (2011). Commercial office plug load savings and assessment: Final report. ECOVA.

Metzger I, Cutler D, Sheppy M (2012). Plug-Load Control and Behavioral Change Research in GSA Office Buildings. Golden, CO, USA: National Renewable Energy Laboratory (NREL).
Nakanishi H (2015). Does telework really save energy? International Management Review, 11: 89-97.

O’Brien W, Gaetani I, Carlucci S, et al. (2017). On occupant-centric building performance metrics. Building and Environment, 122: 373-385.

O’Brien W, Gunay HB (2019). Do building energy codes adequately reward buildings that adapt to partial occupancy? Science and Technology for the Built Environment, 25: 678-691.

O'Brien W, Yazdani Aliabadi F (2020). Does telecommuting save energy? A critical review of quantitative studies and their research methods. Energy and Buildings, 225: 110298.

Ouf MM, O’Brien W, Gunay B (2019). On quantifying building performance adaptability to variable occupancy. Building and Environment, 155: 257-267.

Peng Y, Rysanek A, Nagy Z, et al. (2017). Occupancy learning-based demand-driven cooling control for office spaces. Building and Environment, 122: 145-160.

Rubinstein F, Enscoe A (2010). Saving energy with highly-controlled lighting in an open-plan office. LEUKOS, 7: 21-36.

Schafer L (2013). Schafer: Pitching in is the new rule at Best Buy.

Vuppala SK, Kiran Kumar HS (2013). HPLEMS: Hybrid plug load energy management solution. Energy Procedia, 42: 133-142.

Wardell J, Gittens C (2020). For many, COVID-19 has changed the world of work for good.

Yang Z, Becerik-Gerber B (2014a). Modeling personalized occupancy profiles for representing long term patterns by using ambient context. Building and Environment, 78: 23-35.

Yang Z, Becerik-Gerber B (2014b). The coupled effects of personalized occupancy profile based HVAC schedules and room reassignment on building energy use. Energy and Buildings, 78: 113-122. 